\title{
Fifty Years of Aerodynamics: Successes, Challenges, and Opportunities
}

\author{
T.E. Nelson $*$ D.W. Zingg **
}

\begin{abstract}
This paper presents a review of developments in aerodynamics during the last 50 years. Progress in aerodynamic design, theoretical aerodynamics, wind tunnel testing, and especially computational fluid dynamics (CFD) is discussed. Where appropriate, applications to aircraft design are presented, as are new aircraft concepts. Topics of Canadian interest are presented and the paper includes several examples of research and development in aerodynamics at de Havilland.
\end{abstract}

\section{RÉSUMÉ}

Le document présente une revue du secteur de l'aérodynamique depuis les 50 dernières années. On y traite des progrès réalisés en conception aérodynamique, en aérodynamique théorique, dans les essais en soufflerie et, surtout, en simulation numérique en mécanique des fluides (CFD). Le cas échéant, des applications dans la conception des aéronefs sont présentées, comme de nouveaux aéronefs concepts. Des sujets d'intérêt pour le Canada sont présentés, et le document renferme plusieurs exemples de recherche et de développement en aérodynamique chez de Havilland.

\section{PART I: AIRCRAFT DEVELOPMENT, AERODYNAMIC THEORY, AND WIND-TUNNEL TESTING}

\section{INTRODUCTION}

$T^{\mathrm{i}}$ he Canadian Aeronautics and Space Institute was founded in 1953 during a time of intense research and development in aeronautics following the Second World War. Jet propulsion was enabling the development of high-speed civil transports and supersonic military aircraft. The race was on to build the first generation of jetliners and supersonic interceptors. Wind tunnels were being constructed around the World to support the effort, and Canada was no exception. The National Aeronautical Establishment, (NAE, later the Institute for Aerospace Research or IAR), was founded just two years earlier, in 1951, to focus effort on aeronautical research and began expanding its wind tunnel test facilities. At that time, wind tunnel testing was at the heart of aerodynamic research and was the best method of gathering precise aerodynamic data and assessing new designs. Computational fluid dynamics (CFD) did not really exist as a discipline. The Euler and Navier-Stokes equations were too difficult to solve. Good numerical algorithms had not yet been developed and the rudimentary computers available were not up to the job. Analytic methods for reduced sets of equations, semi-empirical methods, and empirical methods were used to develop new aerodynamic concepts. The results of previous experiments were relied on heavily for developing new designs and a wide variety of design options were thoroughly tested.

Much has changed in the last 50 years. Large jet transports, small jet transports, turboprops, and supersonic fighters have all been developed and are so common that the general public often views aircraft overhead not with wonder but with irritation at the noise. Aerodynamics has changed dramatically as well. In the 1950s aerodynamicists were either theorists or experimentalists (or better yet, a bit of both). Today we are all becoming Computational Fluid Dynamicists. The great effort and advanced mathematics that was once applied to analytical methods has been refocused on numerical methods. Computers are now so fast and numerical solutions are so readily available that CFD is applied not only to the flow around airfoil sections, but also to wings, jet engines, propellers, and even whole aircraft. However, the applications of CFD do not stop there. Much more mundane problems like the flow in air-conditioning 
ducts and cabin ventilation are also tackled. The role of wind tunnel testing has faded to some degree and in many cases the wind tunnels are now used for confirmation rather than development of a new design.

This paper attempts a nearly impossible task, to review progress in aerodynamics and computational aerodynamics over the last 50 years, in just a few pages. Such a topic deserves a book, or perhaps a series, however, we shall attempt to show many of the highlights, with an unavoidable Canadian bias. We must apologize ahead of time for all the contributions that are not mentioned, and we hope no one is offended if their favorite topic or airplane is not presented.

\section{The First 50 Years}

Since last year was the 100th anniversary of the Wright Brothers first flight, any review of the last 50 years must start with a brief review of the first 50 years and a discussion of the state-of-the-art in 1953.

On 17 December 1903, the Wright flyer took to the air for a brief flight of only $12 \mathrm{~s}$ that covered a mere $120 \mathrm{ft}(1 \mathrm{ft}=$ $3.048 \times 10^{-1} \mathrm{~m}$ ) and the age of powered flight was born. Today we would not call it a flight, rather a small skip. However, powered flight started with that small skip, and the Wright Brothers rapidly improved their aircraft so that by 1908 they were ready to show it to the World by touring Europe and flying circuits around the Hunaudieres racetrack in Le Mans, France. The demonstrations drew huge crowds, and the flights were publicized in newspapers around the World. Returning to the U.S.A. in 1909, they flew a long demonstration flight before a million spectators at the Hudson-Fulton Celebration in New York. Many aircraft were built in the next few years by developers in many countries. Canada had its own first powered flight on 23 February 1909 when John McCurdy at Baddeck, Nova Scotia, flew the Aerial Experiment Association's Silver Dart. These early aircraft were biplanes with very thin airfoil sections, pusher propellers, and canards rather than horizontal tails.

Over the next few years many new aircraft configurations were tried with the canard being replaced by a horizontal tail so that

By 1914, the average European airplane was a tractor airplane (i.e., having its engine in front) with a wooden framework covered by doped fabric, and externally braced wings and tail surfaces. Retractable landing gear and such high-lift devices as flaps and slats were things of the future, as were the enclosed cockpit, the controllable pitch propeller, the supercharged engine, and all-metal, internally braced construction. ... Airplanes flew between 60 and 80 miles per hour, ... Some had ailerons for roll control, but most utilized Wright-inspired wing warping. ... Engines were prone to fail, and, contrary to popular belief, prewar and wartime aircraft often had vicious handling characteristics - ... (Hallion, 1984a).

Most First World War aircraft still had very thin wing sections but the benefits of thicker wing sections were demonstrated when the Fokker D-VII biplane flew near the end of the First World War (Anderson, 1997). The D-VII had a powerful engine, a maximum speed of $125 \mathrm{mph}$, a superior rate of climb, and improved maneuverability. The thicker sections provided a higher maximum lift and were not prone to sudden leading-edge stall when maneuvering.

Developments in aerodynamics between the first and second World wars focused on adopting thick airfoil sections, the development of much faster and structurally sound monoplanes, and the development of better flight controls: ailerons, elevators and rudders with spring tabs, trim tabs, and horns. For an excellent review of the status of flight control design in 1945 see Morgan and Thomas (1945). Effective highlift devices were also developed, such as split flaps, invented by Wilbur Wright and J. M. H. Jacobs in 1920, the slotted wing, invented by Handley Page in 1919 and Lachmann in 1918, the automatic slat invented by Handley Page in 1926 (Pleines, 1961), and the Fowler flap invented in 1924 by Harlan D. Fowler (Miller and Sawers, 1968).

Most early aircraft development did not benefit from theoretical aerodynamics. Inventors and engineers developed ideas and tested them either in the wind tunnel or in the sky. They adopted the successes and discarded the many failures. But at the same time, the theorists were developing analytic methods and an understanding of how aerodynamics worked. Key contributions, prior to the First World War, include Prandtl's boundary-layer theory and the lifting-line theory.

The period between the first and second World wars saw the development of important theories for ideal fluid flow, thin airfoil theory, compressible flow, and continued development of boundary-layer theory and wing theory. The best reference during this period is the six-volume series, Aerodynamic Theory, edited by Durand. It includes a historical review and contributions from Prandtl, (viscous flow and boundary-layer theory), von Karman and Burgers (ideal fluid flow), and Betz (airfoil theory). Other topics include flight dynamics (B. Melvill Jones), experimental research (Toussaint and Jacobs), and compressible fluids (G.I. Taylor). Drag rise at transonic speed was recognized as a problem during the 1930s and Adolf Busemann, in Germany, developed the concept of wing sweep in 1935, which would allow aircraft to fly at higher supersonic speeds. The first swept wing fighter, the Me-262 was developed by Germany during the Second World War and had a modest amount of sweep.

So what was the status of aerodynamics in 1953 ? The sound barrier had been broken by Chuck Yeager 6 years earlier in the Bell X-1, and supersonic aerodynamics, in theory and in practice, was progressing rapidly. The United States was developing the Century series of fighters and the first generation of jet transports were also under development. Here in Canada, A.V. Roe was about to launch the Avro Arrow program and at the other end of the scale, de Havilland Canada had developed a small bush plane with short takeoff and landing capability, (STOL), the DHC-2, which would be known as the Beaver. 


\section{The Last 50 Years}

\section{Supersonic Aerodynamics}

When German research was examined at the end of the Second World War, the benefits of wing sweep were immediately appreciated by U.S. scientists and engineers and incorporated into new designs. The first two U.S. aircraft with sweep were both subsonic, the Boeing B-47 bomber with $35^{\circ}$ of sweep (1947) and the F-86 Sabre also with $35^{\circ}$ of sweep. At that time, R.T. Jones at NACA was also developing an understanding of the benefits of sweep and advocating its use for high-speed aircraft. Important contributions to wing theory from that time include Jones' low-aspect-ratio wing theory (Jones, 1946), swept wing theory (Jones, 1947), and wing-body drag theory or supersonic area rule (Jones, 1956; Whitcomb and Sevier, 1960). An excellent review of wing aerodynamics is Jones' 1990 book Wing Theory and the classic text is Ashley and Landahl, Aerodynamics of Wings and Bodies (1965).

Although the Bell X-1, which was the first aircraft to exceed the speed of sound in 1947, had a straight wing, the Bell X-2 included a swept wing. It first flew in 1954 and set a speed record of $2094 \mathrm{mph}$, about Mach 3.2, in 1956 (Bowman, 1990). The development of supersonic swept-wing aircraft was not problem-free. The slender aircraft with relatively small wings developed unexpected stability problems such as roll-inertia coupling, which led to crashes of the X-2 and an X-5 (Day, 1997). For a review of X-plane flight testing see Hallion (1984b). The first production supersonic fighter was the F-100 Super Sabre, which first flew on 25 May 1953 and entered service in 1954.

In Canada, A.V. Roe started the design studies for the CF105 Arrow program in July 1953, under contract to the Department of Defense. The intention was to develop a supersonic all-weather interceptor as a successor to the subsonic CF-100. The specifications called for a crew of two, a range of 600 miles, a speed of at least Mach 1.5, and sufficient maneuverability to pull $2 g$ at $50000 \mathrm{ft}$ without losing altitude or airspeed. The Arrow was a very large fighter with a large very thin delta wing with a wing area of $1225 \mathrm{sq} \mathrm{ft}(1 \mathrm{sq} \mathrm{ft}=$ $9.29030 \times 10^{-2} \mathrm{~m}^{2}$ ) and a leading edge sweep of $61^{\circ}$. Although not as obvious as the wasp shape of the F-102 fuselage, area ruling was used in shaping the forward fuselage, engine intakes, and aft-body of the Arrow. Development was typical of the time and relied heavily on wind-tunnel testing. No less than 17 aircraft and component tests were conducted in wind tunnels at NAE, Cornell, NACA Cleveland, NACA Langley, and MIT. Wind-tunnel testing was limited in speed and model size so drag and stability and control data were also obtained from eleven 1/8th scale free-flight models. These were launched atop Nike rockets at the CARDE range in Ontario and at NACA Langley. The Arrow was a fast aircraft reaching speeds of Mach 1.98 and was predicted to exceed Mach 2.1 with the Iroquois engine. It was also very fast on landing. In the words of test pilot Spud Potocki, "As you probably know the Arrow had no flaps, and was what is known in the business, as a rather "hot" plane" (Arrowheads, 1980).
The lack of good test facilities in Canada, for programs like the Arrow, led NRC to launch the development of the $5 \times 5$ trisonic wind tunnel at Uplands. This blow-down wind tunnel has a Mach number range from 0.1 to 4.25 with a good-sized working section $5 \mathrm{ft}$ square. The tunnel is pressurized, which allows testing at flight or near flight Reynolds numbers. The development program was launched in 1955 . To reduce the program risk, a 1/12th scale pilot tunnel was constructed first, to evaluate the tunnel design. Technical challenges included the design of the test section, the pressure control valve, the diffuser, and the settling chamber (Lukasiewicz, 2000). The test section was designed with porous walls and normal holes were selected, providing a porosity of $20.5 \%$.

The Arrow was cancelled on the notorious "Black Friday", 20 February 1959, and essentially all aircraft, jigs, models, and engineering data were destroyed. The cancellation and the politics surrounding it are well documented in many references (see, for example, Stewart (1988) or Dow (1979)). Our opinion is that Canada would have been much better served by scaling back the program to an affordable level rather than outright cancellation. The job losses would still have been terrible, but the aircraft and the A.V. Roe company would not have been destroyed.

Ironically, the NAE $5 \times 5$ wind tunnel, which was commissioned to support the Arrow program and other new supersonic aircraft, opened in early 1963, well after the end of the Arrow. Canadian industry has not designed a supersonic aircraft since. The $5 \times 5$ wind tunnel has continued, however, performing mostly subsonic and transonic testing. It has had several major upgrades including: the $15 \times 60$ in test section for two-dimensional testing, (1969), vertically translating chokes in the second throat for precise Mach-number control, varying Mach-number runs, (1985), and the Roll-in Roll-out Test Section that included variable porosity walls with $60^{\circ}$ holes, (1989). The tunnel is still actively used today for Canadian aircraft development and has been used by companies and organizations from around the World (Ohman et al., 2001).

\section{Variable Sweep}

The advantages of wing sweep at high speed are a definite disadvantage at low speed. With highly swept low-aspect-ratio wings, the angle of attack needed for low-speed flight is very high, which can make it impossible for the pilot to see the runway. The Concorde and TU-144 later resolved this problem by drooping the nose at low speeds but a better aerodynamic solution is to vary the wing sweep, low sweep for low speed and high sweep for transonic and supersonic flight. Variable sweep was first tested on the Bell X-5 on 20 June 1951. This airplane was based on the Messerschmitt P.1101, which was captured at the end of Second World War. The P.1101 had ground adjustable wing sweep and was intended for research but never flew. The X-5 could vary the wing sweep in flight from $20^{\circ}$ to $60^{\circ}$ and first flew in 1951. It was over a decade, however, until a manufacturer adopted the swing-wing. The first production airplane with a swing-wing, the F-111, flew in November 1964. Several other swing-wing fighters and bombers were developed 
in the following decade including: the Su-17 (1966), the MIG23 (1967), the TU-160 (1981), the F-14 (1970), the B-1 bomber (1974), and the Tornado (1974). Although the swing-wing is an excellent aerodynamic concept, the mechanical system to move the wing and the wing structure are difficult and tend to be very heavy. As a result, since the mid-1970s, no new swing-wing aircraft have been developed.

\section{Supersonic Transports - SSTs}

Success with military supersonic aircraft led manufacturers and governments to advocate supersonic transports during the 1960s. An Anglo-French consortium was developing the Concorde and in the United States Boeing won the competition to develop the U.S. SST with government funding. In 1967, SST's were expected to enter service shortly and be the dominant form of long-haul air transportation. Many airlines wanted the aircraft and Air Canada had options on both the Concorde and Boeing's SST (CASI, 1967). The Russians were also developing an SST, the Tu-144, and were the first to fly on 3 December 1968. The Concorde flew next on 2 March 1969 with the French prototype and on April 9th for the English. The Tu-144 had a double-delta wing and the Concorde had a nicely blended ogive delta wing. These wing planforms provide a good compromise between low-speed and high-speed performance and less movement of the aerodynamic center while passing through Mach 1 when compared with a simple delta. Because the aspect ratio is still low, high angles of attack were needed on landing which obscured the pilot's view of the runway. This problem was solved, not aerodynamically, but mechanically, by tilting the nose down at low speeds. The Concorde entered service on 24 May 1976, but the Tu-144 saw little service and was shelved a decade later. The U.S. SST was dramatically cancelled on 24 March 1971 because of the huge development costs, concerns about commercial viability, fuel costs, and very real noise issues.

Although the Concorde was a great technical achievement, it was a commercial failure. Only 20 aircraft were built and only Air France and British Airways would operate them. In most airspace over land they had to fly subsonically, which reduced their advantage in travel time. Fuel costs were always high, as were ticket prices. Following a crash near Paris on 25 July 2000, caused by runway debris, the Concorde fleet was grounded. The airplane returned to service, briefly, and the last commercial flight of the Concorde was Friday, 24 October 2003.

Since the retirement of the Concorde last year, there are no civil supersonic aircraft in production or in service. However, improvements in propulsion and aerodynamics will undoubtedly result in new supersonic aircraft in the future. The next civil supersonic aircraft will very likely be a business jet. The advantage of high-speed travel will outweigh the added cost for business executives on long flights.

\section{Transonic Aerodynamics}

In the early 1950s, Richard Whitcomb examined wing-body combinations in the $8 \mathrm{ft}$ transonic wind tunnel at NACA's
Langley laboratory and established the transonic area rule (Whitcomb, 1956). Whitcomb concludes:

\section{Near the speed of sound, the zero-lift drag rise of a low- aspect ratio thin-wing-body combination is primarily dependent on the axial development of the cross-sectional areas normal to the airstream. ... \\ Further results have indicated that indenting the bodies of three representative wing-body combinations, so that the axial developments of cross-sectional areas for the combi- nations were the same as for the original body alone, greatly reduced or eliminated the zero-lift drag-rise incre- ments associated with wings near the speed of sound.}

The result was the coke-bottle shaped fuselage, which is evident on many transonic aircraft and supersonic aircraft and delays the onset and reduces the magnitude of drag rise. For high-speed transports, the wing-fuselage junction is usually not modified, but the concept is useful in understanding interference problems. An example is the engine installation on the Global Express and Global 5000 where the aft fuselage was indented to reduce the effects of interference in the junction of the fuselage, fin, engine, and pylon, Figure 1. In this case, a CFD analysis using a transonic small disturbance code was used to assess the modifications (Kafyeke, 1997).

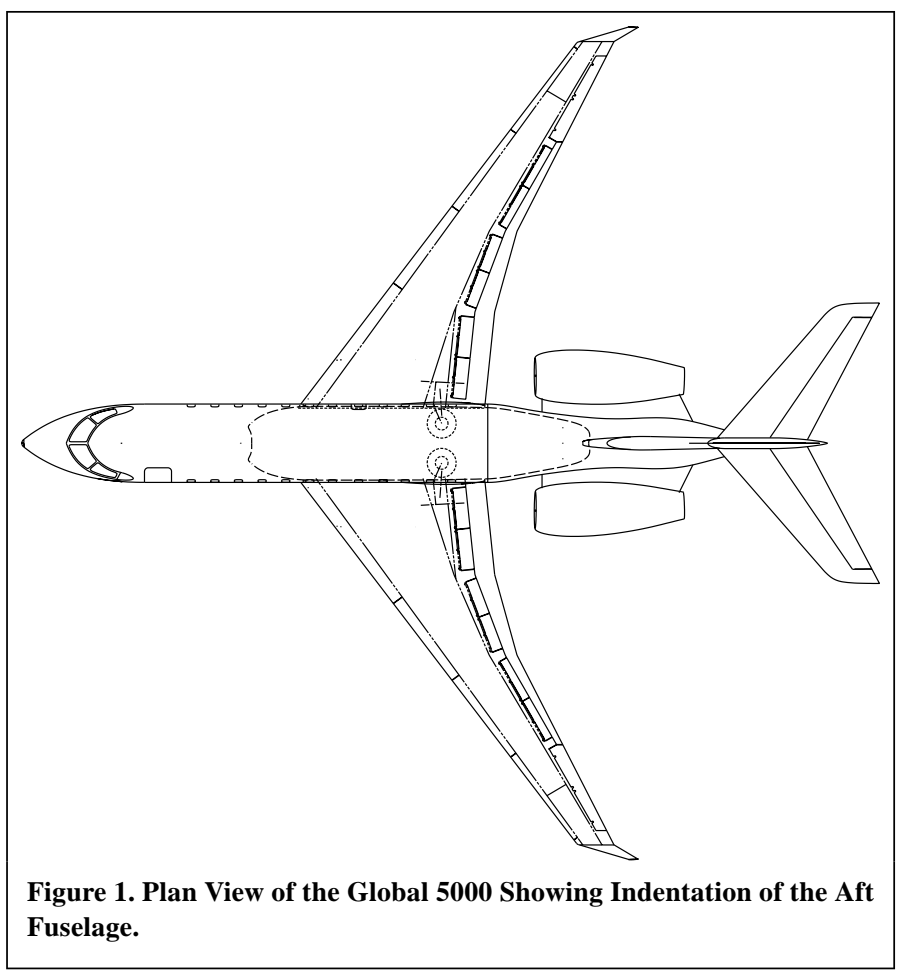

Pearcey, at the National Physical Laboratory (NPL) in the U.K., showed that an airfoil could have a local supersonic pocket but still be shock-free (Pearcey, 1962). In particular, a "peaky" expansion near the leading edge could be used to provide an isentropic recompression further aft. Previously, it was thought that local supersonic flow over a wing would necessarily be terminated by a shock resulting in undesirable wave drag. Whitcomb at NASA, (Whitcomb, 1965) expanded 
on the concept, flattening the upper surface more and adding aft camber giving a larger supersonic pocket. Pearcey's and Whitcomb's work laid the basis for considerable research into supercritical wings both experimentally and theoretically during the late 1960s and 1970s. The advantage of supercritical wings over conventional wing sections is that the leading edge expansion to supersonic speeds creates higher suction on the upper surface thus providing higher lift without wave drag and delaying drag rise. For an aircraft designer, this allows either a higher drag rise Mach number for the same sweep angle and wing thickness, or less sweep for the same drag rise Mach number and wing thickness, or a greater wing thickness (and fuel capacity) for the same sweep angle and drag rise Mach number.

Pearcey's and Whitcomb's shock-free airfoils look quite different. Pearcey's peaky airfoil has a strong leading edge expansion and a smaller supersonic pocket. Whitcomb's introduces high aft camber using a reflex on the lower surface. This provides a higher $C_{\mathrm{L}}$ but can make the airfoil too thin at the aft end. If the aft end is thickened, it can make the trailing edge quite blunt. Figure 2 compares the two airfoils. In Figure 2, a slightly modified Whitcomb section, (Spaid et al., 1983), is presented where some additional thickness has been added near the trailing edge.

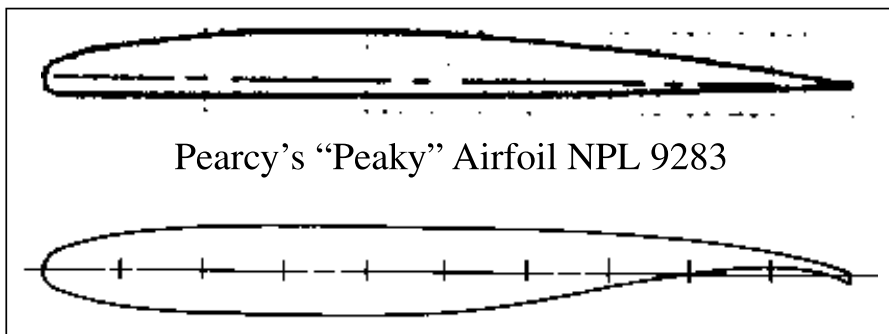

\section{Modified Whitcomb Supercritical Airfoil DSMA 523}

Figure 2. Comparison of Peaky and Aft-loaded Supercritical Airfoils.

The impact of powerful computers and the rapid transition from analytic to computational methods for transonic aerodynamics is best illustrated by the following extract from the preface of Symposium Transsonicum III (Zierep and Oertel, 1989) in discussing the previous symposia:

... in 1962 the analytical methods (hodograph-, parabolic-, characteristic-, integral equation method) dominated. Already in 1975 the center of interest shifted markedly to Computational Fluid Dynamics (CFD). These methods are now the dominating ones.

An experimentalist's view of supercritical airfoil and wing design, without the benefit of CFD, is provided by Pearcey and Osborne (1970), and a good reference for hodograph methods is Boerstoel (1975). CFD methods are addressed in detail in the second half of this paper.

Supercritical airfoils were not immediately incorporated on transport aircraft. The design procedure for the first generation of large jet transports is described by Lynch in 1981:
In the past, including the design of the DC-10, 747, and L1011, the wing design procedure was almost totally based on the use of linearized inviscid computational methods in conjunction with a somewhat cut-and-try experimental program to refine the wing configuration once the planform, type of "conventional" airfoils, average thickness, and design lift coefficient had been determined from a design optimization study.

Local Mach numbers would generally be below $M=1$ everywhere for the long-range cruise condition with some supercritical flow, shocks, and associated wave drag at the maximum cruise condition, which would be dictated by margins to the formation of strong shocks, shock-induced separation, and buffet.

The challenge of supercritical wing design is to have not only a shock-free design point but also a wide operating range, in terms of $C_{\mathrm{L}}$, of low wave drag, while avoiding drag creep (high $C_{\mathrm{D}}$ at Mach numbers below the design Mach number). Also, the benefits of high aft-camber must be traded off with structural requirements and the need to install effective flap systems. Excessive aft-camber can also lead to flow separation on the lower surface of the wing in the cove region resulting in an unexpected drag penalty (Spaid et al., 1983). One of the first aircraft to use a supercritical wing was the Canadair Challenger 600 , which first flew on 8 November 1978. The Challenger was based on the Learstar concept developed by Bill Lear and licensed to Canadair in 1976. The Learstar included a supercritical wing and Canadair proceeded to develop the design into a successful business jet. Today supercritical wings, or some compromise on a supercritical design, are used on most high-speed transports and business jets. Modern wing design is concerned not so much with sectional data as the pressure distribution and shock pattern on the three-dimensional wing, including the effects of interference from the fuselage, engine pylons, and flap-track fairings. It is, in fact, treated as an inverse design problem (Fejtek et al., 2001) or multipoint optimization problem (Tinoco, 1998).

During the late 1970s and early 1980s Brian Eggleston at de Havilland and Denis Jones at NAE developed a series of thick natural laminar flow (NLF) supercritical airfoils for use on a high-speed turboprop aircraft (Eggleston and Jones, 1985). These airfoils were designed using the BGK full-potential code with a coupled boundary-layer method, (Bauer et al., 1977), combined with wave-analysis diagrams. The diagrams supplied the designer with a graphical picture of the effect of surface slope modifications and aided in the iterative development of an airfoil shape (Eggleston, 1977). The resulting family of airfoils is shown in Figure 3. These airfoils can be easily used on a straight tapered wing and are thick enough at the aft end to make them practical for STOL aircraft. The combination of natural laminar flow on a supercritical airfoil provides very low drag for transonic wings. The long run of laminar flow provides low skin friction and the shock-free design eliminates wave drag. 


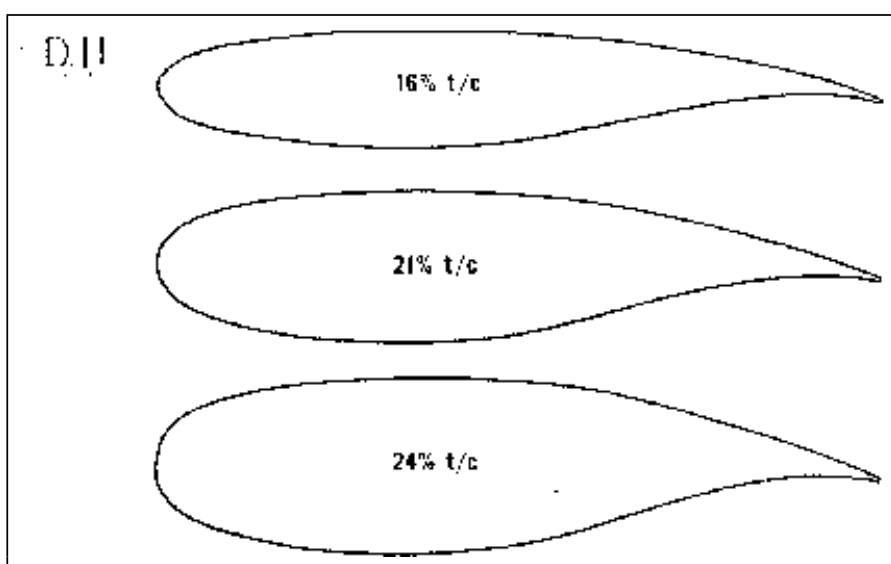

Figure 3. Thick NLF Supercritical Airfoils.

\section{Propeller STOL Aircraft}

Following the cancellation of the Avro Arrow program, the focus of Canadian research and development shifted to STOL. de Havilland had a huge success with the DHC-2 Beaver and followed it up with a larger bush plane the DHC-3 Otter (first flight, 1951). Both aircraft had excellent field performance and could be operated on wheels, skis, or floats. de Havilland then moved into small military transports that had the design objective of supplying troops close to the front line on small semi-prepared landing strips. Both the DHC-4 Caribou (1958) and the larger DHC-5 Buffalo (1964) had excellent field performance. In STOL operations, the Buffalo carrying a payload of almost $12000 \mathrm{lbs}$ could operate out of a $1250 \mathrm{ft}$ strip. In 1961, de Havilland decided to build a larger twinengine bush plane using the new Pratt \& Whitney PT6 turboprop engine. The DHC-6 Twin Otter first flew on 20 May 1965 and was a surprising success. Not only was it a successful bush plane, it was also used very successfully as a nineteen seat regional aircraft. Airlines discovered that they could use the Twin Otter to fly passengers from small regional airports into major airports. There the passengers could switch airplanes for longer flights. All of these early de Havilland aircraft can be considered propeller STOL aircraft and featured thick, lightly loaded wings with powerful mechanical flaps.

Other companies were also interested in STOL technology for both military and civil aircraft. Developments in propeller V/STOL included the Canadair CL-84 tilt-wing demonstrator (1964) and Bell/Boeing V-22 tilt rotor airplane (1989). Of the two concepts, the tilt-wing looks superior from an aerodynamic standpoint since the wing follows the rotors as they tilt. In the tilt rotor, with only the outboard nacelles tilting, the wing causes considerable blockage in the hover configuration resulting in an undesirable fountain effect, reducing lift. On the other hand, the tilt rotor should be more controllable in crosswinds and gusty wind conditions. Despite a very determined development program spanning nearly two decades, the V-22 is still not in service and may not be for several years.
For its next civil transport, de Havilland decided to use propeller STOL technology for a larger, faster regional aircraft, the DHC-7 or Dash 7. The conditions that led to its development and the development of STOL at other manufacturers still exist today. Most airports are secondary and have short runways. They are conveniently located near or in urban areas but are underutilized. The major airports with long runways handle the vast majority of the passenger traffic but are severely congested. The STOL concept for civil aircraft was intended to relieve the congestion by developing the secondary airports for commuter and short-haul traffic. The design objectives for the DHC-7 were: operation from a $2000 \mathrm{ft}$ runway, passenger comfort, and low community noise levels (Buller and Toplis, 1972). To achieve these objectives, the DHC-7 was designed with a large wing with very thick airfoils, powerful double-slotted flaps, and relatively slowly rotating propellers.

It is hard to believe today, but 35 years ago STOL and VTOL were expected to dramatically change aviation in just a few years. To quote John Allen of Hawker Siddeley,

\section{At the present time several developments are proceeding that seem certain to come to fruition during the next cen- tury, such as city centre to city centre VTOL, hypersonic civil and military flight, very large subsonic transports, and so on.}

Enthusiasm for city center to city center STOL or VTOL operations was wide spread and the Canadian government was supportive of STOL research and development. NAE constructed the $30 \mathrm{ft} \mathrm{V} / \mathrm{STOL}$ wind tunnel (now called the $9 \mathrm{~m} \times 9 \mathrm{~m}$ wind tunnel) specifically for V/STOL testing, (Tanguay et al., 2001). A photograph of the newly completed wind tunnel is shown in Figure 4. The first model tested in the tunnel was the DHC-7 model WTBE, which entered the tunnel on 2 July 1970. Figure 5 shows the model in the $30 \mathrm{ft}$ tunnel. Basic stability and control data for power-on and power-off conditions were obtained during the testing. The model included all flight controls, which were instrumented to obtain hinge moment data. Additionally, the aft end of the model incorporated a special balance to obtain fin and tail loads separately from the whole aircraft loads measured on the windtunnel balance. All subsequent de Havilland aircraft have been tested in the $30 \mathrm{ft}$ wind tunnel in the same manner, including the Dash 8 Series.

The Dash 7 entered service in 1977, but sales were disappointing. It was quickly recognized that the STOL market was not developing as expected and led Mike Davy, the vicepresident of engineering at de Havilland, to comment:

The Dash 7 was somewhat misguidedly aimed at the concept of downtown to downtown service, a concept the World has not yet rushed to accept (Davy, 1984).

This was to put it mildly. The Canadian trial for STOLport operations was from a Montreal parking lot to Ottawa's Rockcliff airport from July 1974 to April 1976 using 6 Twin Otters. The trial ran into local opposition, as did proposals for STOL operations nearly everywhere. In Toronto, the Planning 


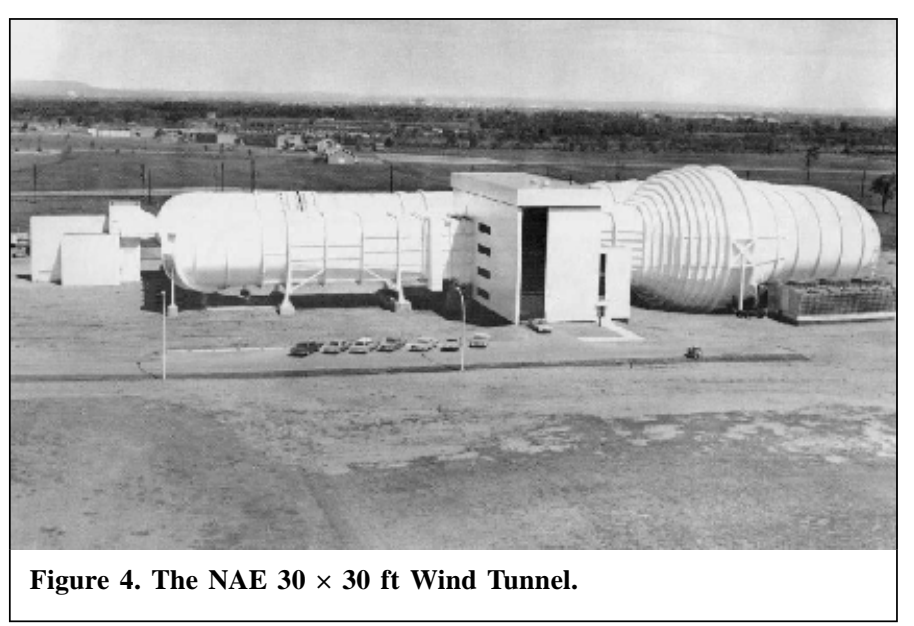

Board recommended against STOL commercial air service at the Toronto Island Airport in 1978 (Barker, 1978). In fact, 25 years later, development of the Toronto Island Airport is still an issue and was debated in the 2003 mayoralty race. Such problems make the prospects of the new BA609 civil version of the V-22 tilt-rotor aircraft look dim as far as commuter sales are concerned although it will likely find a niche in markets normally served by helicopters such as search and rescue and transportation to offshore oil rigs.

\section{The Augmentor Wing}

During the 1960s, while de Havilland was developing successful propeller STOL aircraft, it was also researching ways to apply turbojet and turbofan technology to STOL aircraft. The objective was to develop an aircraft with shortfield performance and jet cruise speeds. Don Whittley was working on the augmentor wing concept where trailing-edge blowing from the main airfoil, between upper and lower flaps, can be used to generate very high lift coefficients. This configuration can provide performance, which is superior to either blown flaps or jet flaps (Whittley, 1967), and the research was supported by both DRA and NASA. After extensive windtunnel testing in the NASA Ames wind tunnels, it led to the modification of a Buffalo for flight testing of the concept. Two modified Rolls-Royce Spey engines were fitted to DHC-5 number 1, Figure 6. Ducting was installed to direct the fan air from the engine to blow between the flaps, over the ailerons and along the fuselage. The design was very successful and the airplane handled well (Canadian Aviation, 1972). The use of cross ducting in the blowing system provided a near perfect balance in roll and yaw during simulated engine failures (Whittley, 1976). However, the system was extremely loud and not suitable for a civil transport.

With civil STOL aircraft prospects looking dim and the augmentor wing looking too noisy, for civil applications in any case, Don Whittley turned the attention of his research group at

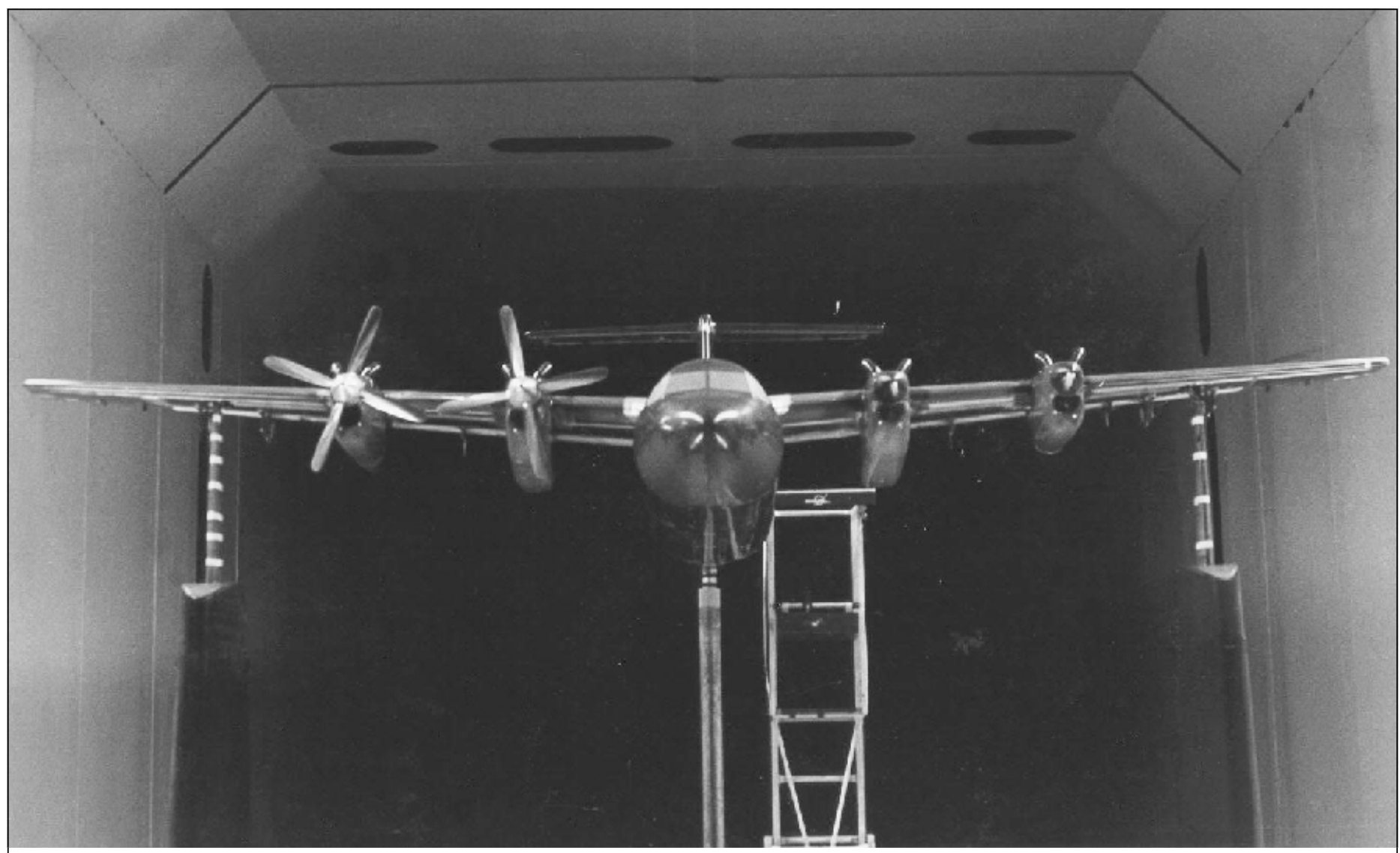

Figure 5. 1/5 Scale Dash 7 Model WTBE in the $30 \times 30 \mathrm{ft}$ Wind Tunnel. 


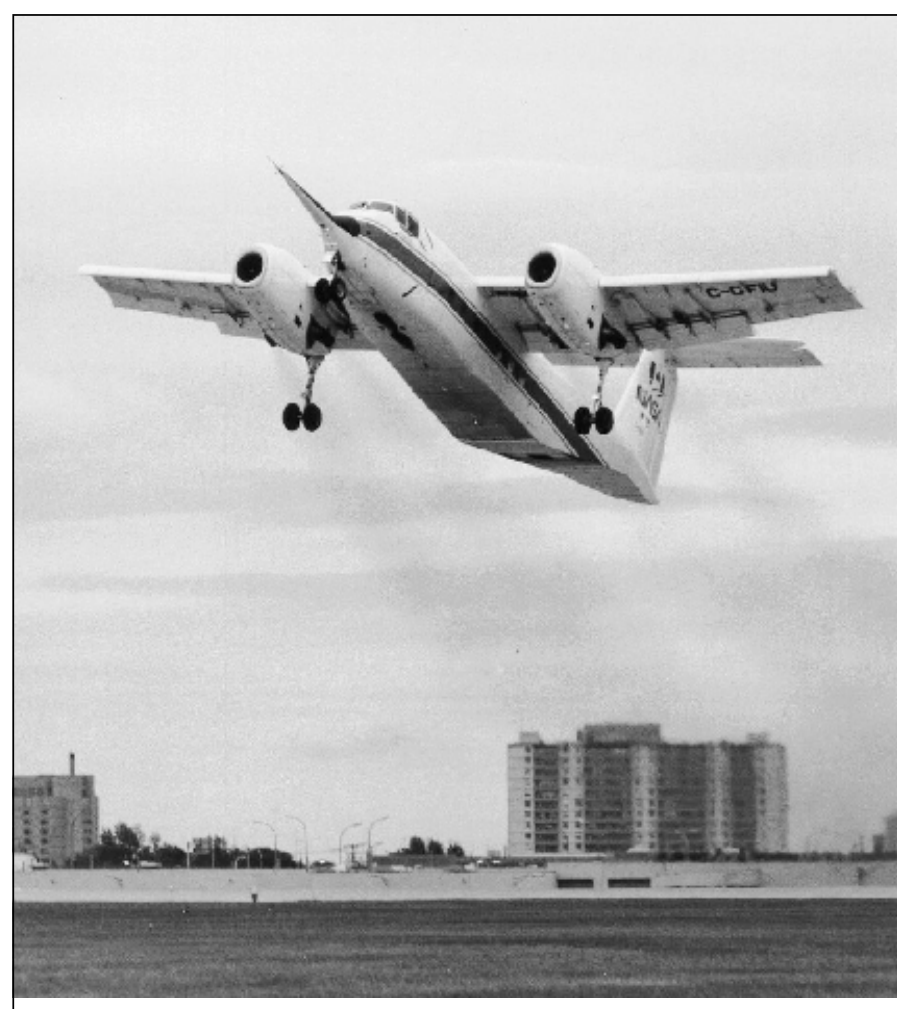

Figure 6. Augmentor Wing Demonstrator Aircraft DHC-5 Number 1.

de Havilland to military applications of the augmentor wing and potential STOL military transports and V/STOL fighter aircraft. Considerable research and development into highspeed straight and swept augmentor wing aircraft with STOL capability and nozzle designs for V/STOL fighters was undertaken during the next decade. A comparison of an augmentor wing section with a conventional section on the C$130 \mathrm{H}$ Hercules, is shown in Figure 7. This augmentor wing section is $24 \%$ thick versus $18 \%$ for the Hercules section and is aimed at a higher cruise speed, Mach 0.66 versus 0.50 . It would also have the benefit of much greater fuel capacity (Lye, 1987). V/STOL fighter concepts were developed in cooperation with NASA. Ejector development was undertaken at de Havilland and wind-tunnel tests were conducted at NASA Ames, (Whittley and Koenig, 1980). The final fighter research model tested was the E7A STOVL fighter, which was tested at NASA Ames in $40 \times 80 \mathrm{ft}$ wind tunnel in 1988 and in the $80 \times 120 \mathrm{ft}$ wind tunnel in 1989 (Poppen et al., 1991). The E7A model in the $80 \times 120 \mathrm{ft}$ wind tunnel is shown in Figure 8. Following this test, Boeing, which owned de Havilland at the time, quietly shut down the augmentor wing research program, not because it was a failure aerodynamically, but to concentrate the company's effort on civil and in particular, regional aircraft.

\section{Beyond STOL - Regional Aircraft}

Development of the 36 passenger Dash 8 airplane in the early 1980s was aimed at the regional, (then called commuter), aircraft market. Good field performance was still a requirement, $3000 \mathrm{ft}$ for takeoff and landing, but STOL

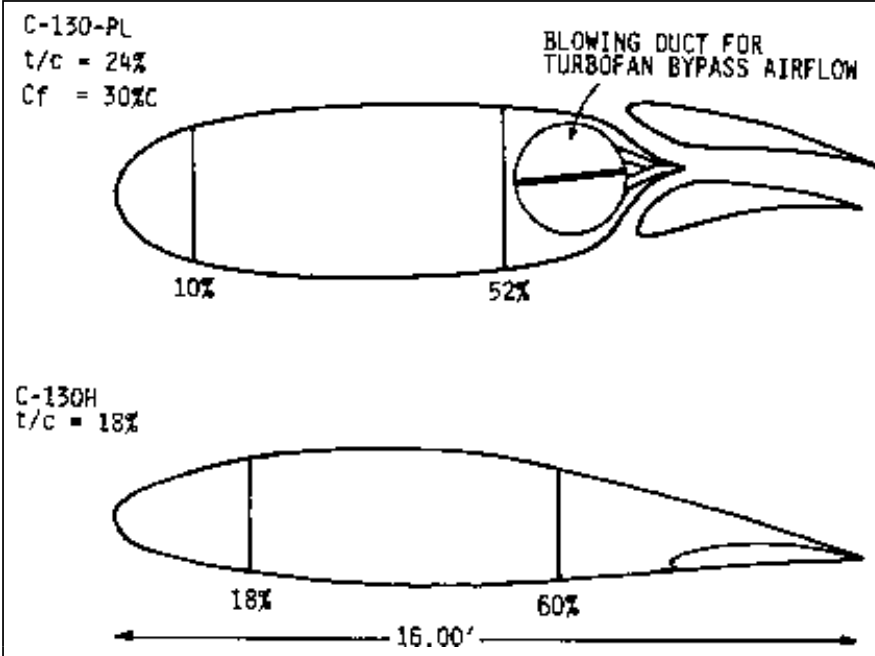

Figure 7. Comparison of Augmentor Wing and Conventional Airfoils for the $\mathbf{C}-130 \mathrm{H}$ Aircraft.

operations were not necessary (Jackson, 1982). Dash 8 development relied heavily on wind-tunnel testing for the evaluation of various design options that were developed using, primarily, panel methods. Panel methods were used for analysis of the whole aircraft, without coupled boundary-layer analysis. Panel methods with a coupled boundary layer were used for two-dimensional analysis and design of the thick wing sections and flaps. Both direct analysis and inverse methods were employed, and separated-flow modeling was included to predict maximum lift (Eggleston, 1984). The wing design features a high aspect ratio of 12 , thick airfoils, $18 \%$ t/c at the wing root and a large single slotted Fowler flap, 39\% chord. Candidate wing sections were tested extensively in the NAE $5 \times 5$ wind tunnel with the $15 \times 60$ in insert (Poole and Teeling, 1981). de Havilland also developed a research propeller using a strip analysis technique, (Borst, 1973), and used a new series of propeller airfoils for the design (Eggleston and Barber 1987). The new 0.6 scale research propeller was tested in the $30 \times 30$ wind tunnel at NAE using a rig developed for large-scale testing (Barber 1983). Although this propeller was not used on the Dash 8, it provided basic data for propeller performance and installation effects and allowed de Havilland to demand design improvements from the propeller manufacturer, Hamilton Standard.

Turboprop aircraft, developed by many manufacturers, dominated the regional aircraft market during the 1980s and de Havilland stretched the Dash 8 to get the 50 passenger Dash 8 Series 300. In the late 1980s, Canadair, then owned by Bombardier, launched a regional jet program. The Canadair CRJ design was based on the successful Challenger business jet and it entered service in 1992. The CRJ was a huge success, prompting development of stretched 70 and 90 seat versions. These small jets, together with the Embraer 145, largely displaced turboprop aircraft in the regional market during the 1990s. On 9 December 2003, Canadair delivered the 1000th CRJ, 11 years after entry into service. 


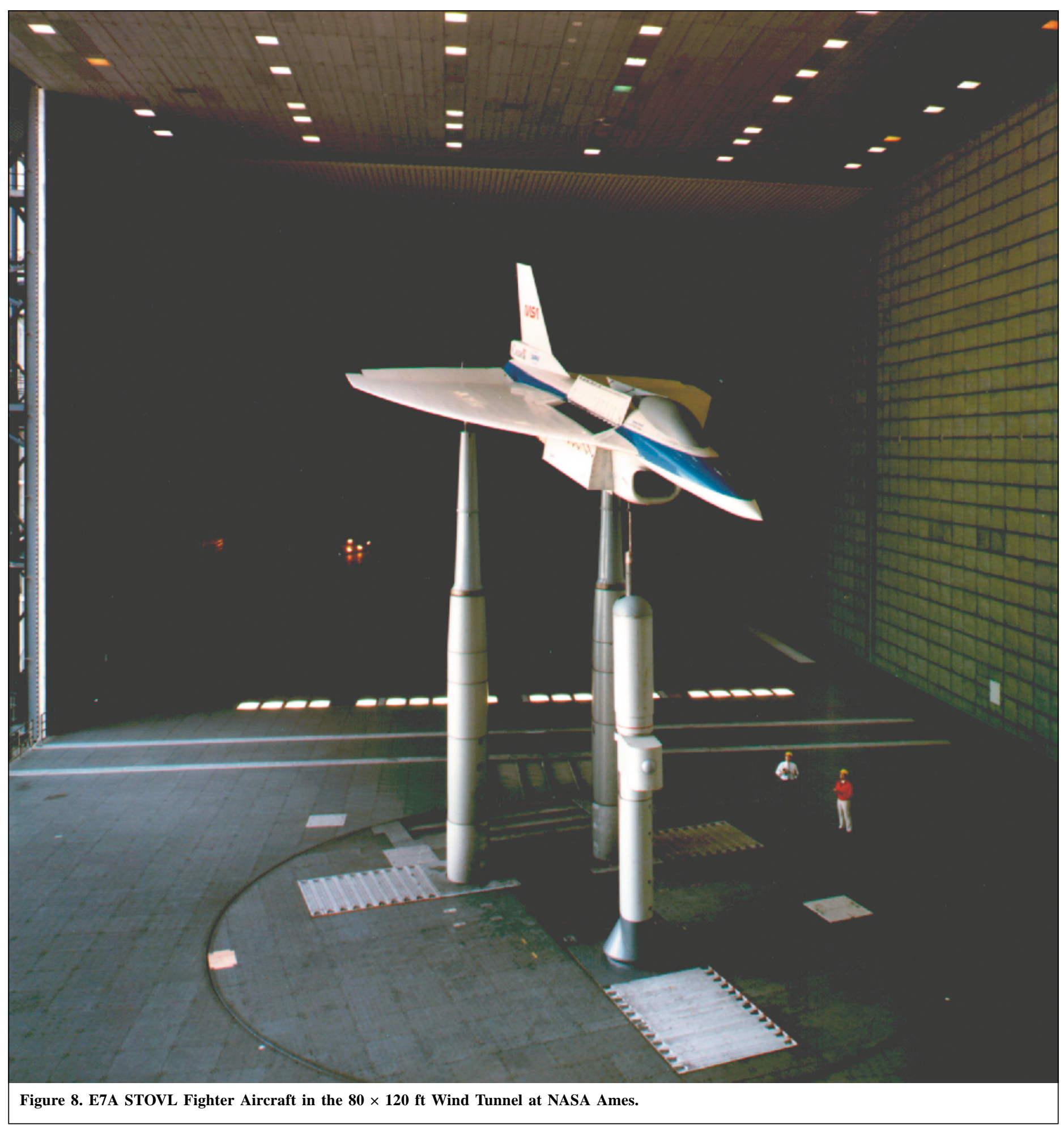

\section{Advanced Propellers, Prop-Fans, and Unducted Fan (UDF) Research}

As a result of rapidly increasing fuel costs in the 1970s, much research was undertaken to explore the possibility of advanced turboprops to replace turbofans on transonic aircraft. Significant fuel savings, perhaps as much as $30 \%$, may be obtained by using propellers with 8,10 or more blades rather than ducted fans. But to operate effectively at transonic speeds the propeller blades need to be very thin and (or) swept and rotate relatively slowly. In the U.S.A., NASA sponsored the Advanced Turboprop Project to fund development. A single rotating 8-bladed prop-fan demonstrator was developed by Hamilton Standard and flight tested a Gulfstream II at speeds up to Mach 0.89 in 1987. General Electric developed the 16 bladed counter-rotating UDF, which was flight tested in 1986 and 1987 on a Boeing 727 at speeds up to Mach 0.84 at 
$39000 \mathrm{ft}$. A later version of the UDF with 10 blades on the forward stage and 8 on the aft was flight tested on a McDonnell-Douglas MD-80 in 1987. Boeing, McDonnellDouglas, and Lockheed all studied advanced propeller installations for new aircraft and retrofit. Boeing's configuration included aft fuselage-mounted engines and was called the 7J7. The McDonnell-Douglas also placed the engines at the back like an MD-80 and was called the MD-91X (Hager and Vrabel, 1988).

At de Havilland, the initial design objective was to develop a high-speed STOL aircraft. Such an aircraft would include many of aerodynamic features being researched. A straight or slightly swept high-aspect-ratio wing with large flaps for good field performance, thick supercritical airfoil sections for a cruise speed of $M=0.70$, and 8-bladed prop-fans for high thrust at low speed, excellent efficiency at cruise, and low noise in all phases of flight (Eggleston, 1978). The emphasis on STOL was gradually dropped as research continued on potential regional aircraft. Research models of a supercritical high-wing aircraft were tested with both a turboprop nacelle and an ADP installation (advanced ducted propulsor - essentially a very high bypass turbofan), see Figures 9 and 10. In Figure 9, the wing on the turboprop installation is swept at $15^{\circ}$ and in Figure 10, with the ADP installation, it is straight. Eightbladed prop-fan models are shown in Figures 11 and $\mathbf{1 2 .}$

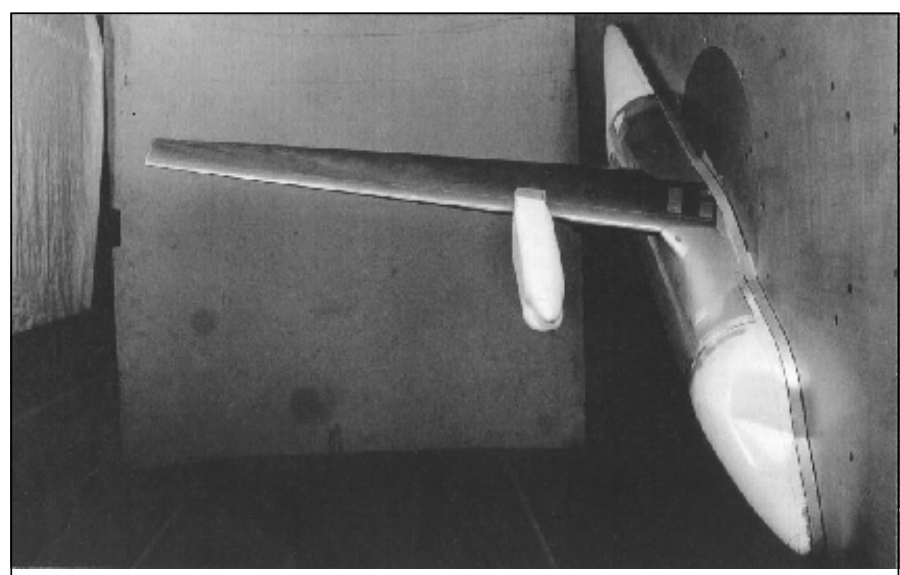

Figure 9. de Havilland Supercritical High Wing Aircraft 1/2 Model WTEY with Turboprop Nacelle.

Although a transonic civil transport airplane with a UDF was never put into service, the legacy (or perhaps just an echo) of advanced propeller research can be seen on the swept propeller tips on the Lockheed 130J Hercules, the SAAB 2000, the Dash 8 Series 400, and most recently, the Hamilton Sunstrand NP2000 propeller for the E-2 and C-2. That is not to say that high-speed propeller transports were never constructed. The military counter example is, of course, the Tupolev TU-95 (Bear), which has four engines, a swept wing and reaches speeds of Mach 0.83 at $25000 \mathrm{ft}$ or 0.78 at $41000 \mathrm{ft}$. However, its counter-rotating propellers appear quite conventional, and by all accounts it was an extremely noisy aircraft. As such, it belongs in the previous generation of turboprops prior to the advanced propeller research.

\section{The Dash 8 Series 400}

After several delays, de Havilland, now owned by Bombardier, launched the Dash 8 Series 400 program in 1995. The Series 400 turboprop was intended not only as a stretch of the Dash 8 Series 300 from 50 seats to 70 but also as a highspeed alternative to jets. Although, $M=0.7+$ turboprops were being researched, the Series 400 objectives were more modest since the aircraft was to be a derivative with minimum change. The target cruise speed was $M=0.65$, but this was later scaled back to $M=0.60$ over concerns about tail buffet at dive speeds. Field performance was less important than on previous de Havilland aircraft and a target of around $4000 \mathrm{ft}$ was acceptable. This allowed the wing loading to increase to the relatively high level of about $95 \mathrm{lbs} / \mathrm{sq} \mathrm{ft}(1 \mathrm{lb} / \mathrm{sq} \mathrm{ft}=$ $4.88243 \mathrm{~kg} / \mathrm{m}^{2}$ ). In comparison, the wing loading on a Dash 7 is only about $50 \mathrm{lbs} / \mathrm{sq}$. ft.

Aerodynamic changes from the Series 300 included: a modified wing inboard of the nacelle, a new flap for the inboard wing, a new nacelle for the larger PW150 engine, a new engine installation, and a new exhaust arrangement. The horizontal tail area was increased by $20 \%$, its leading edges were modified and powered elevators were incorporated. A new wing root fairing was designed and a bullet fairing was added at the junction of the fin and horizontal tail to improve buffet margins. Many CFD codes were used during the design. Twodimensional panel methods with a coupled boundary layer, as well as the BGK code were used for the wing modifications. Drela's Euler and coupled boundary-layer code MSES, (Drela and Giles, 1987), was used for the inboard flap modifications, as was the Navier-Stokes code TORNADO, developed with the University of Toronto Institute for Aerospace Studies (UTIAS) (Nelson et al., 1994). The panel method VSAERO (Maskew, 1982) and Euler code MGAERO (Epstein et al., 1989) both from Analytical Methods Inc. were used during development of the nacelle, wing root fairings, and bullet fairing. For a comprehensive review of CFD development and applications at de Havilland, see Fejtek (2001).

Fourteen wind tunnel tests were included in the development program, with most testing taking place at NAE (now called IAR) in Ottawa. Two-dimensional tests in the $5 \times 5$ tunnel at IAR with the $15 \times 60$ in insert included: three wing sections with and without flaps and one wing section with aileron. Tests in the $5 \times 5$ tunnel included: a 1/10th scale empennage model and a $1 / 24$ th scale plate mounted aircraft model to acquire, primarily, drag data, see Figure 13. Testing in the IAR $6 \times 9 \mathrm{ft}$ wind tunnel included: a reflection plane aircraft model, a nacelle installation, $1 / 4$ scale empennage model, and 2 lowspeed isolated propeller tests. High-speed tests of a $1 / 4$ scale propeller were undertaken in the transonic wind tunnel at ARA in the U.K. Full scale testing of the PW150 engine and intake in icing conditions was performed by Pratt $\&$ Whitney Canada in the propulsion wind tunnel at IAR. The final test in the development program was a $1 / 4$ scale powered aircraft model, 


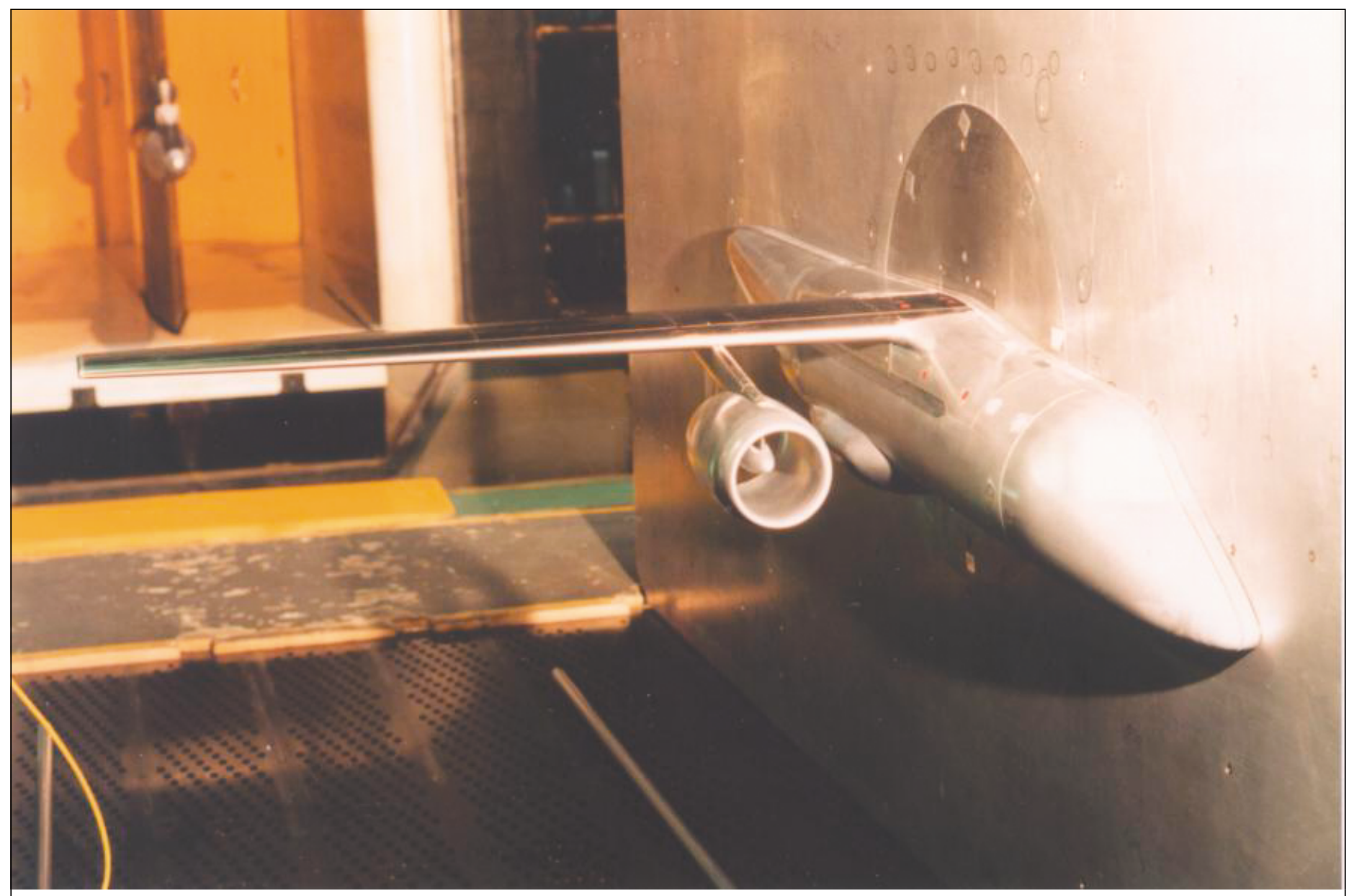

Figure 10. de Havilland Supercritical High Wing Aircraft 1/2 Model WTEY with ADP Nacelle.

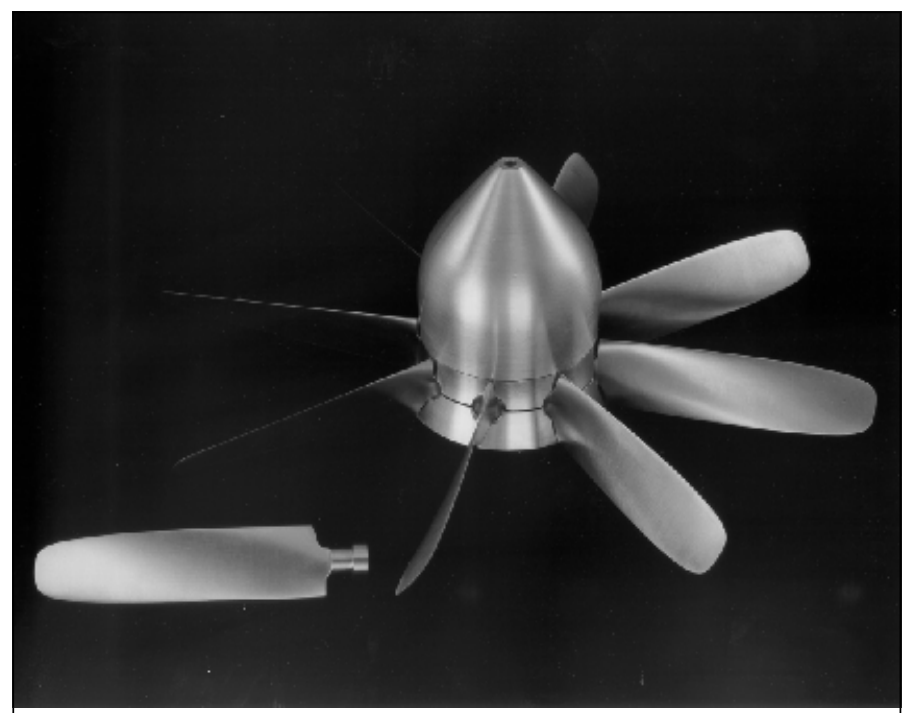

Figure 11. de Havilland 8-Bladed Advanced Propeller Research Model WTGC4.

which was tested in the $30 \times 30 \mathrm{ft}$ tunnel at IAR. This model included: operating control surfaces, which were instrumented to obtain hinge moments; adjustable flaps; and $200 \mathrm{HP}$ variable-speed water-cooled electric motors driving the sixbladed propellers.

The wind-tunnel test program was largely uneventful with test results very much as predicted up until the $1 / 4$ scale full aircraft tests. This testing revealed that at high power, low speed, and flaps retracted with moderate to high angles of attack, the aircraft had a minor directional instability for small angles of sideslip. What this means in flight is that at low weight, low speed, and high power (the most rapid climb condition), the airplane would want to climb with the nose $5^{\circ}$ to $10^{\circ}$ to the left, or $5^{\circ}$ to $10^{\circ}$ to the right but the pilot would not be able to hold the airplane steady at any position in between. For larger sideslip angles, either left or right, the aircraft was stable. This result demonstrates the continuing value of wind-tunnel testing. No CFD results up to that point had indicated any problem. A variety of modifications to promote directional stability were tested in the wind tunnel with support from CFD analysis. The final choice was the addition of fuselage strakes, as shown in Figure 14, which modify the airflow on the aft fuselage and empennage. Due to uncertainties about Reynolds number effects, three configurations from the wind-tunnel tests were selected for flight testing. Not surprisingly, the best configuration from the wind tunnel was also the best in flight 


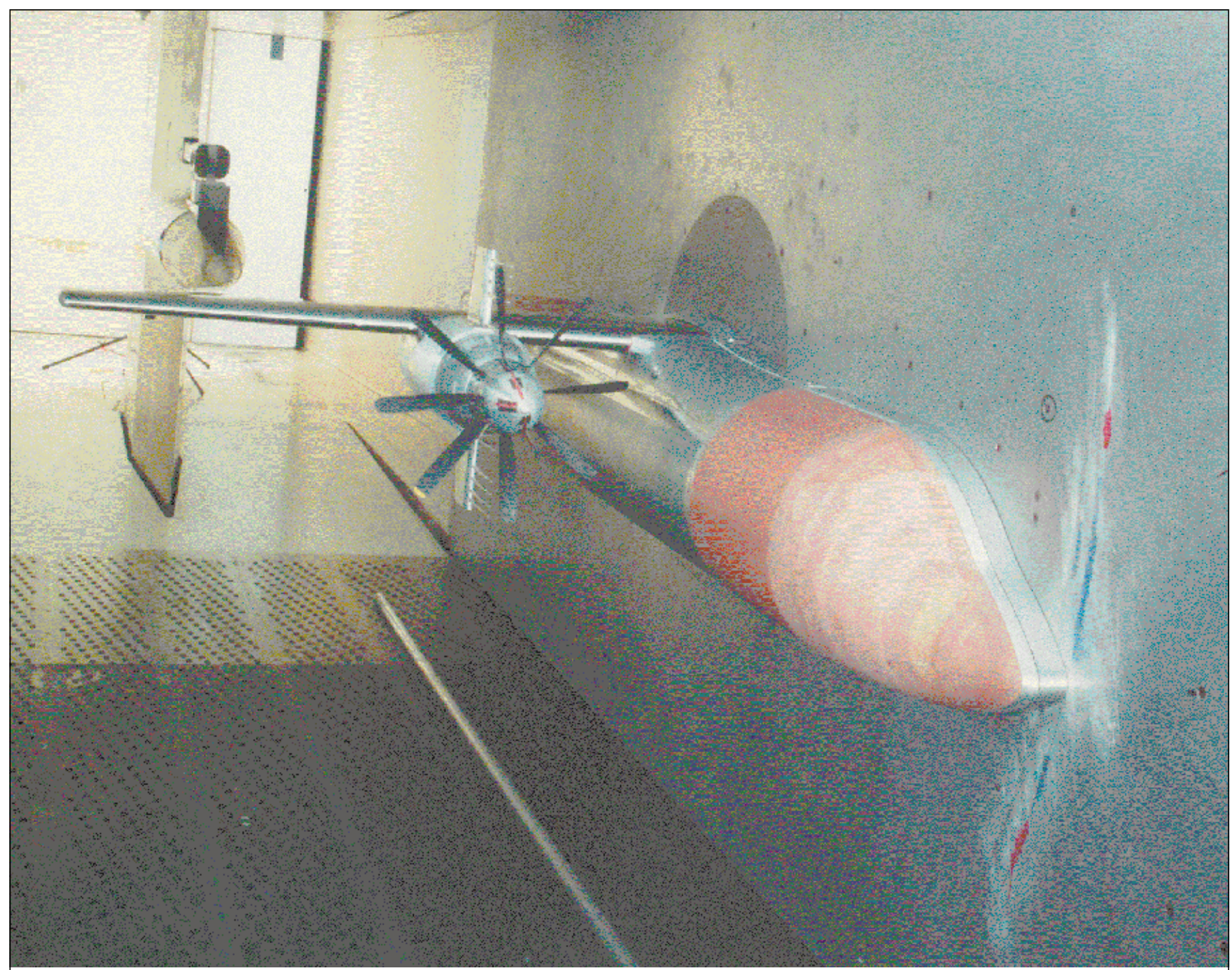

Figure 12. de Havilland 8-Bladed Advanced Research Propeller Installed on Aircraft Half-Model WTEJ.

and the instability discovered in the tunnel was also present in flight - although not quite as pronounced.

One additional wind-tunnel test on the Dash 8 Series 400 took place in September 2000 after the certification flight testing was complete. During the flight test program, Mother Nature had not cooperated in providing good test conditions for taxiing in high crosswinds. As a result, the propeller had only been cleared, from a loads standpoint, for taxiing in cross winds of up to 45 knots. Rather than wait for suitable test conditions, it was decided to perform a test in the NASA Ames $80 \times 120 \mathrm{ft}$ wind tunnel. The whole aircraft was loaded into the tunnel as shown in Figure 15. This test was interesting because a complete operational aircraft was tested, including running engines and with a crew of 3 on board. Unlike most wind tunnel tests, the nose of the airplane was not pointed down the length of the tunnel and into the wind. The airplane spent much of the test facing sideways, with the pilots looking at the tunnel wall. Yaw angles of $142^{\circ}, 225^{\circ}$, and $270^{\circ}$ were tested and strain gauge measurements were taken from one of the propellers, successfully clearing the airplane for taxiing in cross winds up to 65 knots (Lye et al., 2002).

\section{The Future of Aerodynamics - The NeXT 50 Years}

Making predictions about the future development of technology can be an embarrassing undertaking. In just a few years, predictions can look very foolish when development proceeds more rapidly or less rapidly or in a direction different than expected. For example, Professor W.H. Pickering of Harvard University in 1908 stated:

It is doubtful if aeroplanes will ever cross the ocean, and despite Wright's success they offer little menace to warfare. The public has greatly overestimated the possibilities of the aeroplane, imagining that in another generation they will be able to fly to London in a day. This is manifestly 


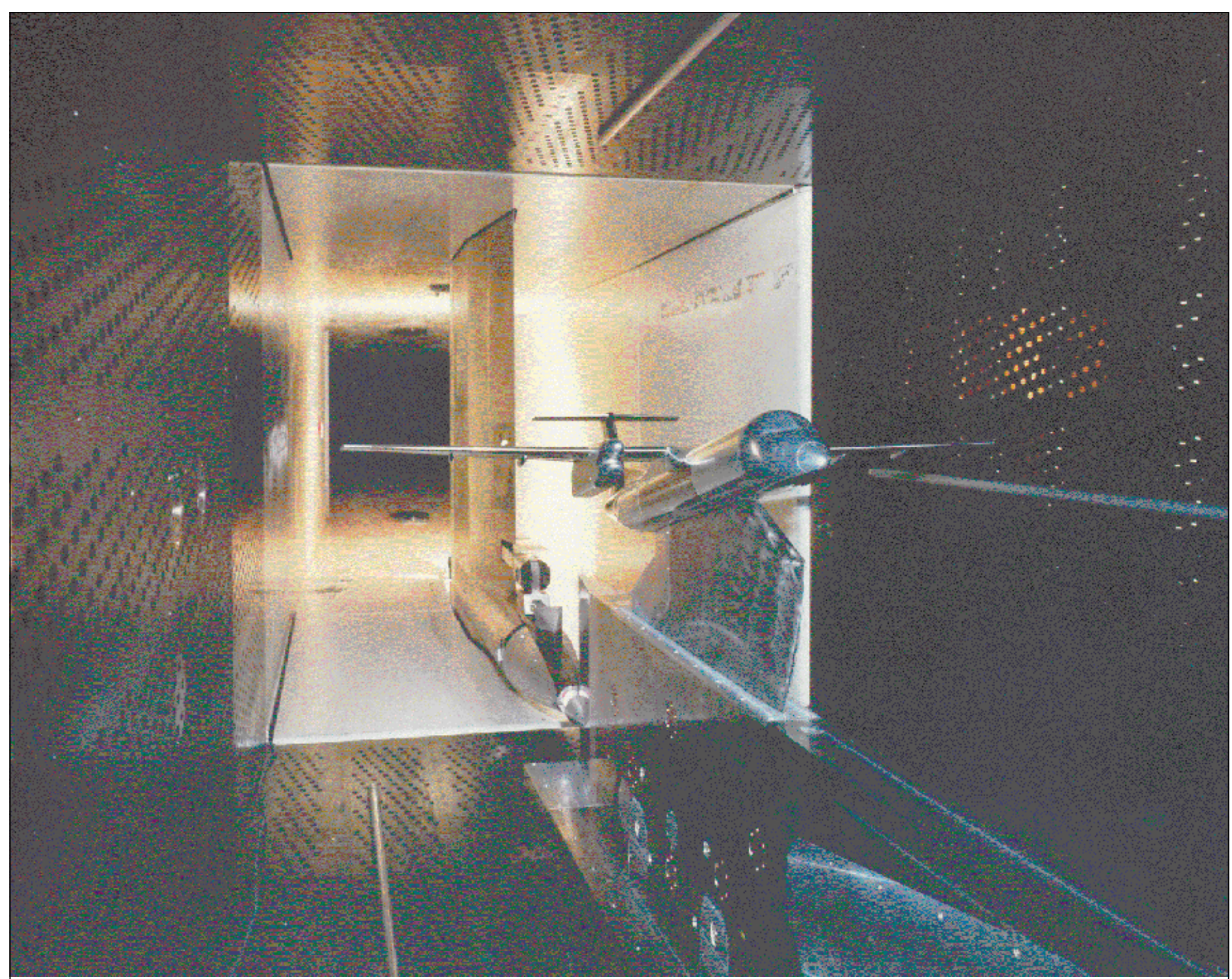

Figure 13. Dash 8 Series 400 Model WTET in the IAR $5 \times 5$ Wind Tunnel.

impossible, because as the speed of an object through the air is doubled the resistance is quadrupled. [Allen, 1970].

He correctly pointed out the physical problem of form drag increasing in proportion to $V^{2}$ but did not anticipate any improvement in streamlining, propulsion, or structural design.

In 1970, the Future of Aeronautics was published for the Centenary of the Royal Aeronautical Society and authors were asked to make predictions for the next 100 years. Many authors predicted V/STOL aircraft as the way of the future, including A.H. Stratford (1970). Thirty years on, it's safe to say the V/STOL is not the way of the future and predictions that cities would need one VSTOL port for each $21 / 2$ million people, (giving London 4 or 6!), now seem ridiculous. Large airports are going to get larger and ways must be found to cope with the congestion. Aircraft will have to be larger, although it may be quite a while yet before we see the 1000 seat transport, which Stratford expected by the mid-1990s. Airbus has targeted the high end of the market and is developing the A380 with

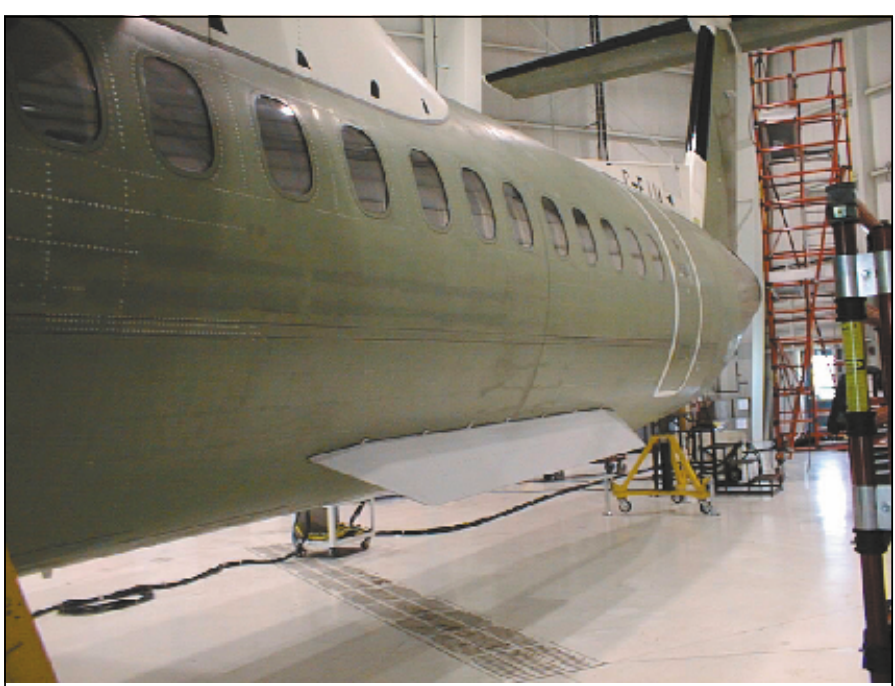

Figure 14. Fuselage Strakes on the Dash 8 Series 400. 


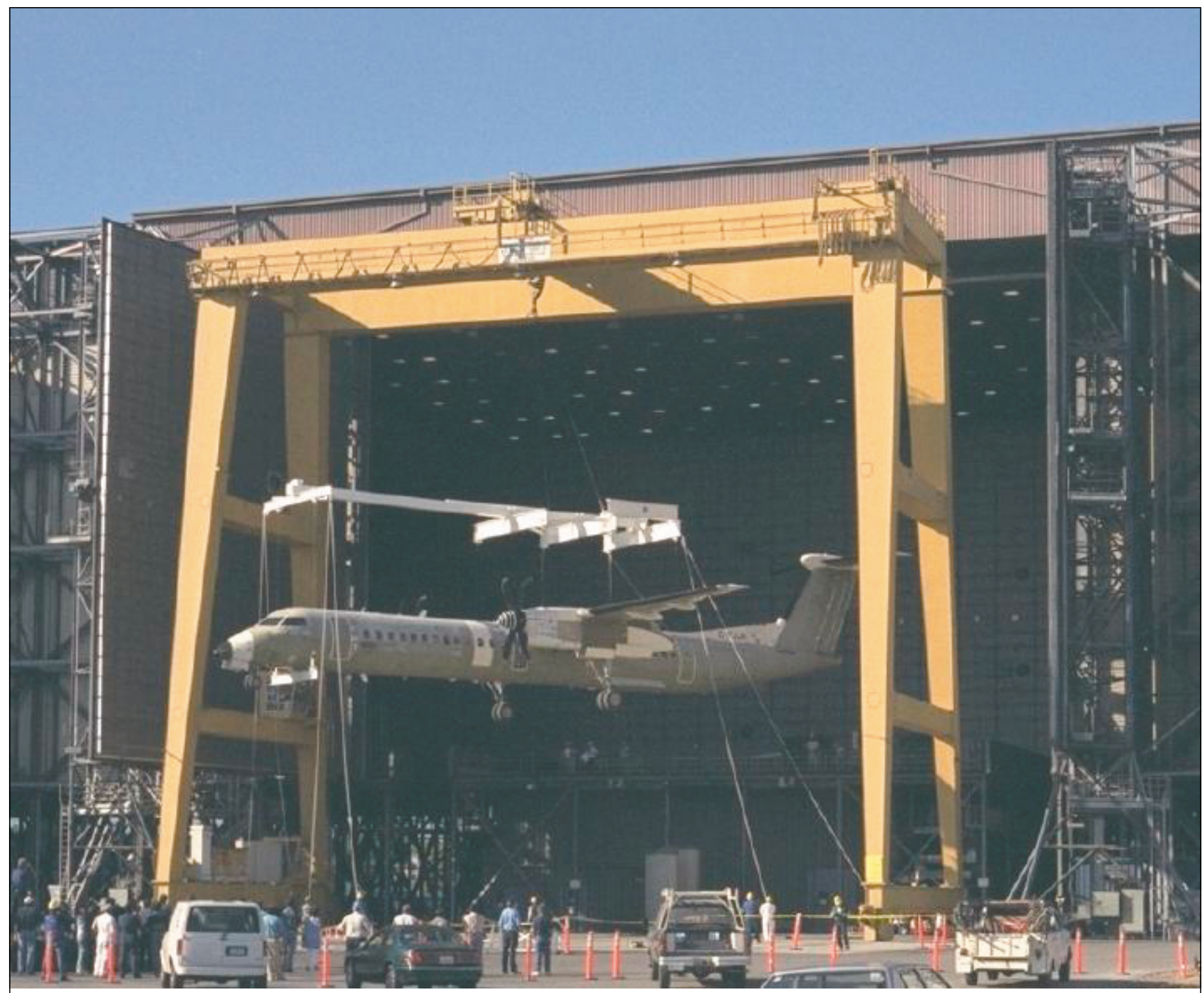

Figure 15. Dash 8 Series 400 Aircraft Number 4001 Being Loading into the $80 \times 120 \mathrm{ft}$ Wind Tunnel at NASA Ames.

555 seats. Boeing on the other hand has chosen to improve its aircraft in the middle of the market with the 7E7 (a 767 replacement with 200-250 seats) rather than develop a new aircraft, larger than the 747. Subsonic transports will nudge ever closer to Mach 1, with the cruise speed dictated by the best trade-off between speed and fuel efficiency. Regional jets and turboprops are getting larger as well. Aircraft in the range of 19-40 seats are being replaced with those in the 50-70 seat range with higher-speed jets favored over more fuel-efficient turboprops.

New supersonic transports seem very unlikely at the moment, as do hypersonic transports. The SST has gone the way of the airship and may never make a comeback. A supersonic business jet looks like a viable design but the market for speed may be too small since most business flights are transcontinental not transoceanic. Hypersonic designs always seem a decade or two away, but lately hypersonic aircraft seem unlikely to ever happen
- at least for civil applications. The failure of NASA's unmanned X-43A hypersonic demonstration aircraft in 2001 has put developments in hypersonic research and scramjet technology back quite a few years if not another decade.

Fuel efficiency, which was very important in the 1970s and 1980s and less important in the 1990s will no doubt become more important sometime in the future. This will spur development of more efficient propulsion systems and drag reduction. High fuel costs will favor the development of efficient high-speed turboprops over jets. However, even using advanced prop-fans or UDFs there is a penalty to pay in community noise for large and very large high-speed transports. This may prevent them from being adopted in spite of significant improvements in fuel efficiency. Prop-fans appear beneficial for smaller transports and regional aircraft. With cruise speeds up to Mach 0.7 they would provide a fuel efficient and quiet alternative to jets. 
The wind tunnels of today are more productive and accurate than ever. In spite of many predictions that CFD would replace the wind tunnel, there is no indication it will happen soon, if ever. However, with the business cycle in the aircraft industry, wind tunnels can have long slack periods. There has been a consolidation in the aircraft industry so there are more wind tunnels than needed. NASA decided in 2003 to mothball some Ames wind tunnels, including the $80 \times 120 \mathrm{ft}$ wind tunnel. If they are not reopened by the end of this year, they will be closed permanently (NASA, 2004). IAR has done well to adapt their wind tunnels for other testing and keep them fully utilized. In addition to aircraft research and development they are also used for truck, car, and building tests (Zan et al., 2001; Tanguay et al., 2001).

At the moment, we seem to be in a period of evolution and refinement in aerodynamic design rather than revolution. There is no shortage of revolutionary concepts, however. Flying wing transports, morphing wings, the sonic cruiser, and remotely piloted fighter aircraft have all been proposed and may be developed. As for the future of CFD that topic is covered in Part II of this paper.

\section{PART II: A BRIEF HISTORY OF COMPUTATIONAL AERODYNAMICS}

\section{INTRODUCTION}

$\mathrm{W}$ e describe developments in computational aerodynamics over the past fifty years and conclude with a discussion of current challenges. The reader should be aware that this is not a comprehensive review of the field; rather it is weighted toward more recent developments and to the second author's experiences. Furthermore, the emphasis is on external aerodynamics. Applications to turbomachinery and other propulsion-related flow fields are not covered.

There have been a number of papers written recently presenting an historical overview of some aspects of computational fluid dynamics (CFD). ${ }^{1}$ A particularly worthwhile example was written by MacCormack (1993). It is strengthened by many warm descriptions of some of the CFD pioneers with whom MacCormack worked at the NASA Ames Research Center. The second author has had the good fortune to associate with some of the same individuals and strongly endorses the descriptions of Harvard Lomax, Dick Beam, and Bob Warming as gentlemen of great intelligence and integrity. The second author would like to add Bob MacCormack himself as well as Tom Pulliam and Marcel Vinokur to the list of those combining a vast knowledge of CFD with an unselfish and helpful nature.

\section{EARLY DAYS}

The field of computational aerodynamics was envisaged almost as soon as computers were developed. In 1946, Alan Turing remarked that the new computer he was instrumental in developing, “... would be well adapted to deal with heat transfer problems, at any rate in solids or in fluids without turbulent motion"(Hodges, 2000). A news report of the same year even more optimistically predicts contributions to aerodynamics: "Revolutionary developments in aerodynamics, which will enable jet-planes to fly at speeds vastly in excess of that of sound, are expected to follow the British invention of "Ace", which has been commonly labelled the electronic "brain" " (Hodges, 2000). A paper by Von Neumann and Richtmyer (1950) submitted in 1949 includes many of the ingredients of modern CFD.

CFD is primarily concerned with the numerical solution of the Euler and Navier-Stokes equations. Pioneering work in the solution of these equations was performed at Los Alamos and the Courant Institute (Lax, 1954; Lax and Wendroff, 1960). Important work by Godunov (1959) was also performed during the 1950s. However, such methods did not have an impact on aerodynamics until somewhat later. During the 1960s, panel methods (Hess and Smith, 1966) were the technique of choice in aerodynamics.

A panel method provides an efficient technique for solving incompressible, irrotational, inviscid flows that are governed by the Laplace equation. The solution is found by superposing singularity solutions of this linear equation. The singularity distribution is calculated such that the boundary conditions, and in the case of a lifting body, the Kutta condition, are satisfied. Once the singularity distribution is determined, it is a straightforward matter to determine surface pressures. The great efficiency of this technique relates to the fact that no mesh is needed in the flow domain; thus the tedious mesh-generation process is avoided. Despite the limited applicability of their solutions, which are accurate only for flows at relatively low Mach numbers with fully attached boundary layers, panel methods remain the appropriate technique for many aerodynamic calculations, especially early in the design cycle.

A key limitation of an incompressible inviscid solution is its inability to provide a prediction of drag (other than induced drag). This was addressed by using solutions of the boundarylayer equations to modify the inviscid solution to account for viscous effects. Many techniques exist for solving the boundary-layer equations. Two of the most successful are the integral approach typified by Green's method (Green et al., 1973) and the finite-difference approach pioneered by Cebeci and Smith (1974). ${ }^{2}$ Aspects of viscid-inviscid matching are discussed by Lock (1981) and LeBalleur (1982). When flow separation occurs, the boundary-layer equations are normally

\footnotetext{
${ }^{1}$ Rather too many, as this reinforces the erroneous notion that the field is mature.

${ }^{2}$ Coincidentally, Tuncer Cebeci and John Green were invited speakers at the 2003 Aerodynamics Symposium of the Canadian Aeronautics and Space Institute. Cebeci spoke about methods that follow naturally from his earlier work. Green spoke about the need for the international aeronautics community to reduce the environmental impact of aircraft (Green, 2003).
} 
solved in inverse form, and a semi-inverse or quasisimultaneous viscid-inviscid matching technique is used.

To obtain solutions at transonic speeds, the boundary-layer solutions can be coupled to inviscid solutions of the fullpotential or Euler equations. Drela et al. (1984) developed a powerful method for coupled Euler and boundary-layer solutions capable of both analysis and design of twodimensional airfoils. The Euler equations are solved using an intrinsic streamline grid, and the coupled system is solved using Newton's method. This led to the airfoil development system MSES, which has been widely used for airfoil design (Drela, 1993).

\section{Algorithms And Meshing}

During the 1960s, an important foundation for future developments in CFD was laid, typically in the context of supersonic and hypersonic blunt body flows. This is not covered here because of our focus on subsonic and transonic aerodynamic flows. In this section, we discuss algorithmic developments for the full-potential, Euler, and Navier-Stokes equations, beginning with MacCormack's method.

In 1969, MacCormack (1969) presented an extension of the Lax-Wendroff method for solving the compressible NavierStokes equations. In the mid-1970s, MacCormack's method was applied by Shang and Hankey (1975) to a turbulent supersonic flow at a Reynolds number of ten million. However, through the 1970 s the aerodynamics community primarily concentrated its efforts on the transonic small disturbance equation and the full potential equation. Murman and Cole (1971) introduced the idea of type-dependent differencing in the solution of the transonic small disturbance equation in 1971. This paved the way for numerical solution of the full potential equations applicable to inviscid compressible flows with weak shock waves. Jameson (1973) performed an early calculation of a three-dimensional transonic flow over a yawed wing, and Holst and Ballhaus (1979) developed a numerical scheme for the full potential equation in conservation-law form.

The Lax-Wendroff and MacCormack methods are combined space-time discretizations. Although they were very popular and successful, they have some drawbacks. In particular, they are both explicit. Subsequent methods most often treat the discretization of space and time separately. Through spatial discretization, the governing partial differential equations are converted to a system of ordinary differential equations (Lomax et al., 2001). For time-accurate computations these equations can be integrated using timemarching methods developed for ordinary differential equations. Such methods can also be used to compute steady solutions, or the time derivative can be set to zero and the resulting system of nonlinear algebraic equations can be solved using an iterative technique. The next two sections discuss developments in spatial and temporal discretization, respectively.

\section{Spatial Discretization}

One of the difficulties faced in developing solution techniques for the Euler equations is that the eigenvalues of the flux Jacobian are of mixed sign for subsonic flows. As a result, one-sided differencing is unstable. The Lax-Wendroff and MacCormack methods address this difficulty, since they are dissipative independent of the sign of the wave speed (Lomax et al., 2001). In the late 1970s, Moretti (1979) and Steger and Warming (1981) introduced alternative ways of addressing this issue inspired by the method of characteristics. As a proponent of shock fitting, Moretti was a central figure in the debate between shock fitting and shock capturing, ${ }^{3}$ which was eventually decided in favour of shock capturing.

The Moretti and Steger-Warming papers sparked a period of intense activity in the development of upwind schemes and eventually high-resolution upwind schemes. Van Leer (1982) improved upon the flux-vector splitting concept, which gave way to a flux-difference splitting approach more suited to finite-volume methods (Roe, 1981, 1986; Osher, 1984). Fluxdifference splitting can be viewed in a number of different ways. The derivation for linear systems given in Lomax et al. (2001) parallels flux-vector splitting; in the linear constantcoefficient case the two approaches are essentially identical. ${ }^{4}$ Alternatively, flux-difference splitting can be viewed as a generalization of Godunov's method permitting extension to higher orders of accuracy and approximate Riemann solvers. The approximate Riemann solver of Roe is particularly important and ubiquitous. It is based on a linearization about an average state (the Roe average) such that one-sided differencing is achieved in supersonic flow, and the RankineHugoniot conditions are satisfied across shock waves. Van Leer (1979) developed a second-order extension of Godunov's scheme and introduced many of the ideas that paved the way for further development of high-resolution schemes.

In parallel with upwinding, solvers were developed using a combination of centered differencing with "artificial dissipation" (Jameson et al., 1981; Pulliam and Steger, 1980). Jameson et al. (1981) introduced a scalar artificial dissipation scheme that became very popular because of its robustness and simplicity. This approach is excessively dissipative in boundary layers and can require very fine meshes to obtain meshindependent computations of drag and boundary-layer properties. Swanson and Turkel (1992) introduced a matrix scheme for artificial dissipation that alleviates this shortcoming. Although it was not conceived as such, the scalar scheme can be seen as a simplified version of the matrix scheme in which the matrix in question is replaced by its spectral radius. The matrix scheme is very closely related to upwinding.

\footnotetext{
${ }^{3}$ A term coined by Harvard Lomax.

${ }^{4}$ For nonlinear systems, the differences are subtle but important.
} 
The solvers of Jameson et al. (1981) and Pulliam and Steger (1980) utilize a simple sensor based on the normalized second difference of pressure to detect shock waves. When a shock wave is detected, a second-difference dissipation scheme (which is first-order) is used. This is necessary to avoid oscillations near shocks. Elsewhere, in smooth regions of the flow, a fourth-difference dissipation scheme (which is thirdorder) is used. This pressure switch is quite effective for transonic aerodynamic flows. However, it is not adequate for more complex flows. For example, it cannot detect a contact discontinuity, where pressure is continuous. During the 1980s, the concept of preserving monotonicity (or positivity, which is closely related) was formalized, leading to robust and accurate high-resolution schemes.

The development of high-resolution schemes is based on the work of Lax (1972), who observed that, in the solution of a nonlinear scalar conservation law, the total variation of a differentiable solution between any pairs of characteristics is conserved. The total variation decreases if there are discontinuities that satisfy an entropy inequality. It is evident that there are potential benefits if numerical schemes can be designed to incorporate this property. Godunov proved that linear schemes that preserve monotonicity are restricted to firstorder accuracy. In 1983, Harten (1983) introduced non-linear total-variation-diminishing (TVD) schemes to address this difficulty. The basic idea is to use a flux limiter to limit the higher order flux near discontinuities such that the discrete total variation diminishes, and oscillations are not produced. Contributions to the development of practical flux limiters were made by many researchers, including Yee (1985), Venkatakrishnan (1995), who addressed the issue of limiters preventing convergence to steady state, and Barth and Jespersen (1989), who provided a popular approach for unstructured grids. As shown by Harten and Osher (1987), TVD schemes are at most second order. This led to the development of essentially non-oscillatory schemes that are not subject to this restriction (Harten and Osher, 1987; Harten et al., 1987). Recent work on ENO schemes for unstructured grids has been performed by Ollivier-Gooch (1997).

Most of the flow solvers in practical use for aerodynamic calculations are second-order accurate in space. Some solvers use a third-order upwind-biased discretization for the convective terms, but the viscous terms are almost always second order. Furthermore, the formulation for the convective terms often reduces to second order on a non-uniform grid. Zingg et al. (2000) showed that a uniformly third-order accurate spatial discretization (De Rango and Zingg, 2001) can be very efficient for highly accurate computations of steady aerodynamic flows. The small increase in the computing expense per grid node is easily offset by the substantial reduction in grid nodes needed to achieve target accuracy levels.

In the numerical solution of practical aerodynamic problems, spatial discretizations based on finite-element, finitedifference, and finite-volume methods have all been used with success. At this stage, finite-volume methods are most popular as a result of their applicability to unstructured meshes (a property shared by finite-element methods) and their inherent conservation property. Furthermore, much of the highresolution framework has been developed for finite-volume methods. Recently, the discontinuous Galerkin method has also garnered considerable interest.

In parallel with developments in accurate spatial schemes, meshing schemes have been developed for application to complex geometries. Most of the early work using both finitedifference and finite-volume methods was done using structured meshes. Finite-difference methods are generally implemented using a curvilinear coordinate transformation (Vinokur, 1974; Pulliam, 1986). Three approaches are used for generating structured meshes, algebraic (Eiseman and Smith, 1980), elliptic (Thompson et al., 1985), and hyperbolic (Steger and Chaussee, 1980). Extension to complex geometries is achieved through multi-block (Weatherill and Forsey, 1984) or overlapping (Benek et al., 1985) meshes.

A key disadvantage of multi-block grids is the problem of defining the appropriate topology for a complex geometry, which is difficult to automate. This has not kept such grids from being used for impressive calculations over complete aircraft configurations (Piperni and Boudreau, 2003). However, it does represent an impediment to further automation of the process. Furthermore, structured grids are rather restrictive when it comes to solution adaptation. These issues have motivated serious research into solvers for unstructured grids and associated mesh generation and adaptation techniques since the late 1980s. A nice overview of unstructured grid flow solvers was provided by Venkatakrishnan (1996).

Key contributors to the development of algorithms for unstructured grids include Barth (1995), Mavriplis (1990, 1995), and Venkatakrishnan and Mavriplis (1993). Contributions to methods for solution adaptation are too numerous to mention. Noteworthy Canadian contributions include Trepanier et al. (1991) and Habashi et al. (1997 or 1998). An important recent development is the ability to associate the error estimates driving the adaptation with specific functionals of interest using the solution of an adjoint problem (Giles and Pierce, 2002; Venditti and Darmofal, 2003). This is a key step toward the development of solution adaptation techniques with prescribed error bounds in key quantities.

Unstructured grid flow solvers and associated grid generation technology are very effective for inviscid flows, where isotropic grids are appropriate. For high-Reynoldsnumber turbulent flows, high-aspect-ratio grid cells are needed in boundary layers. This creates difficulties for both unstructured grid solvers as well as solution adaptation methods. One solution is to use prismatic cells in boundary layers and isotropic tetrahedra elsewhere. However, this increases the complexity of both the solver and the grid adaptation. Further research is needed to develop algorithms for grid generation, flow solution, and adaptation to achieve the 
potential of unstructured grids to provide a highly automated process.

Cartesian grids with adaptive mesh refinement (AMR) (Berger, 1984) provide an extremely efficient alternative for the solution of the Euler equations about complex geometries. This approach greatly reduces the user expertise and effort in the mesh generation process (Aftosmis et al., 1998). Impressive results have been obtained for both steady (Aftosmis and Berger, 2002) and unsteady (Murman et al., 2003) flows over highly complex geometries. Sachdev et al. (2003) present an extension of the AMR approach to curvilinear meshes.

\section{Time-Marching and Iterative Methods}

Time-marching methods for ordinary differential equations are typically classified as explicit or implicit, but in reality the distinction is more subtle. An implicit method requires the solution to some tolerance of a linear system of equations (at least) at each time step. If the iterative method used to solve the linear system is fundamentally explicit, then the approach will suffer from many of the shortcomings of an explicit method. It is most accurate to classify methods in terms of a continuous scale from fully explicit to fully implicit, with many popular methods lying somewhere in between. The principle disadvantage of an explicit method lies in the time step restriction associated with conditional stability. Hence, stiffness is the enemy of explicit methods. One of the main causes of stiffness is the high-aspect-ratio nature of the mesh cells needed for efficient discretization of high-Reynoldsnumber turbulent flows.

Jameson et al. (1981) presented explicit multi-stage schemes based on Runge-Kutta methods for efficient solution of the Euler equations. With the addition of implicit residual smoothing and multigrid (Brandt, 1977), rapid convergence was obtained for the Euler equations (Jameson, 1983). Extension to the Navier-Stokes equations was accomplished by Martinelli et al. (1986). This effective algorithm has been used in many flow solvers and applied to countless computations of aerodynamic flows.

In the late 1970s, Beam and Warming $(1976,1978)$ and Briley and MacDonald (1977) developed an implicit approximate factorization algorithm that has also become the basis for many flow solvers. With this approach, the implicit operator matrix is factored such that each factor is a block tridiagonal or block pentadiagonal matrix when the database is suitably permuted. Thus, the algorithm is implicit along mesh lines in a structured mesh. With the diagonal algorithm of Pulliam and Chaussee (1981), the factors are further reduced to scalar tridiagonal or pentadiagonal form. The cost of solving these banded systems is much lower in both computing time and memory than a complete lower-upper decomposition of the unfactored matrix operator. The price paid is that the algorithm no longer converges rapidly as the time step tends toward infinity, as in the unfactored case (Lomax et al., 2001). Although a suitable time step must thus be selected for optimal convergence, the time step is much less restrictive than that for an explicit method, and the algorithm is extremely effective on meshes with high-aspect-ratio cells. The approximate factorization algorithm has been used in numerous computations of practical aerodynamic flows (Jespersen et al., 1997).

With increases in computer speed and memory, it has become possible to solve the unfactored matrix associated with an implicit algorithm directly for problems of increasingly large size. Hence, one can consider the use of Newton's method to solve the coupled system of nonlinear algebraic equations arising from the spatial discretization of a steady flow problem. Bailey and Beam (1991) successfully applied Newton's method to the two-dimensional compressible Navier-Stokes equations in 1991. However, this approach remains impractical for threedimensional computations at the time of writing. In contrast, spurred by the development of the generalized minimal residual algorithm (GMRES) for non-symmetric linear systems (Saad and Schultz, 1986), inexact Newton methods have become very competitive (Pueyo and Zingg, 1998). This approach is particularly effective when used in the context of aerodynamic optimization together with the discrete adjoint method, since the preconditioned Krylov method (GMRES) can also be used to solve the adjoint problem efficiently (Zingg et al., 2003).

Many flows of interest in aerodynamics are unsteady. The implicit approximate factorization algorithm can be applied to a time-accurate computation with second-order accuracy through a linearization in time (Lomax et al., 2001). Recently, it has become more popular to solve the non-linear problem arising at each time step of an implicit method using an algorithm for steady flows, such as an explicit-multigrid, approximate factorization, or inexact Newton algorithm. This is similar to solving a steady problem at each time step, albeit with an excellent initial guess. This approach, sometimes described as dual time stepping ${ }^{5}$ (Venkateswaran and Merkle, 1995) has several advantages. It permits low-Mach-number preconditioning, which improves both convergence rate and accuracy (Venkateswaran and Merkle, 1995), allows rather straightforward implementation of implicit block and interface conditions, avoids a loss of accuracy from a loosely coupled turbulence model, and enables orders of accuracy higher than second order.

\section{Application to Turbulent Aerodynamic FLOWS}

In Turing's remark quoted earlier, his optimistic outlook for computational heat transfer was restricted to "solids and fluids without turbulent motion". He was prescient in identifying turbulence as a serious obstacle. Nevertheless, a number of approaches have been developed that enable accurate solutions to be obtained for complex turbulent flows. There is a large turbulence modelling community that has generated a

\footnotetext{
${ }^{5}$ When the algorithm used to solve the non-linear problem is a time-marching method.
} 
hierarchy of turbulence models. However, few of these models have had an impact on the aerodynamics community. One of the earliest turbulence models used for aerodynamic computations was the algebraic model of Cebeci and Smith (1974), which is used in the solution of the boundary-layer equations. Lomax and Baldwin (1978) extended the model for use in Reynolds-averaged Navier-Stokes (RANS) solvers. Despite the shortcomings inherent in an algebraic model, the Baldwin-Lomax model was the dominant model in RANS solvers for aerodynamic flows throughout the 1980s. In 1992, Spalart and Allmaras (1992) developed a one-equation model that has several advantages and has become the turbulence model of choice. It is relatively accurate in predicting separation points, wakes, and shock-boundary-layer interactions and is quite easy to implement on structured and unstructured grids. Menter (1993) developed a zonal twoequation model that is also quite effective, but studies such as Godin et al. (1997) show that the Spalart-Allmaras model is somewhat more accurate.

More recently, Spalart $(2000,2001)$ has proposed a hybrid of RANS and large-eddy simulation (LES) that targets highReynolds-number separated flows, known as detached-eddy simulation (DES). Good results have been obtained for several flows, and this approach is expected to gain in popularity for complex flows, especially since it will be some time before LES is feasible for practical problems in aerodynamics.

In 1987, Holst (1987) summarized the results of a workshop in which several attached and separated transonic flows over airfoils were solved using 23 different solvers, including RANS, coupled-Euler/boundary-layer, and coupled-fullpotential/boundary-layer solvers. There is a fair bit of scatter in the results, especially as the extent of turbulent boundary-layer separation increases. Subsequent grid resolution studies by the second author (Zingg, 1992) demonstrated that most of the grids used in the workshop were much too coarse to produce grid-independent results, especially in skin friction and drag.

Ten years later, Fejtek (1997) summarized the results of a similar workshop for a high-lift three-element airfoil in a takeoff configuration. Again, a range of flow solvers were used, including panel and full-potential methods coupled with boundary-layer methods, as well as incompressible and compressible RANS solvers. ${ }^{6}$ Excellent results were obtained using the compressible RANS solvers, primarily with the Spalart-Allmaras and Menter turbulence models. The greatest disagreement among the solvers occurs in the vicinity of maximum lift. Fejtek concludes with a discussion of sources of error other than the turbulence model (which had become a convenient scapegoat for all errors), including insufficient grid density, inadequate distance to the far-field boundary, and improper specification of transition location.

Rumsey and Ying (2002) provide a thorough review of capabilities of predicting high-lift flows as of 2002. Many excellent results computed using various solvers are presented, but difficulties remained in the prediction of flows with a large amount of separation as at maximum lift. In an important subsequent paper, Rumsey et al. (2003) showed that much of the disagreement between computation and experiment near maximum lift is associated with substantial spanwise pressure variation in the experiment. The experimental angle of attack at maximum lift can vary by as much as $2^{\circ}$ depending on the sidewall venting pattern. This paper highlights the need for further careful experiments to provide a database needed to ascertain the validity of current RANS solvers for such flows. If such solvers are to be used with numerical optimization to determine optimal geometries, a high degree of confidence must be established in the ability of the solvers to predict subtle effects on maximum lift.

\section{Aerodynamic Design and Optimization}

Through a cut-and-try process, an aerodynamic analysis capability can be used for aerodynamic shape design. However, it is much more efficient to use an inverse technique or numerical optimization. The panel methods discussed previously have the useful property that they can be used to solve the inverse problem, that is to find the shape that produces a specified pressure distribution. The designer must choose the pressure distribution to meet the specified design goals. In particular, the concave pressure recovery associated with incipient turbulent boundary-layer separation devised by Stratford (1959) was useful in the design of airfoils for high lift (Liebeck, 1973) and high-lift-to-drag ratio (Zingg, 1983). Giles and Drela (1987) developed an efficient inverse design method based on the coupled Euler and boundary-layer equations.

Although the inverse approach provides a useful aerodynamic design tool, it still requires great expertise on the part of the designer in tailoring the pressure distribution to meet both on- and off-design performance goals. It is primarily useful in two dimensions. Consequently, it was recognized early on that numerical optimization could provide an even more powerful tool (Hicks et al., 1974). However, the cost of numerical optimization was simply too high at that time. Using finite differences to calculate the gradient involves a cost of roughly one flow solve per design variable. Therefore, a problem with twenty design variables, for example, and requiring, say, twenty optimizer iterations requires over 400 flow solves. The challenge was to find a more efficient way of calculating the gradient.

The adjoint method introduced by Pironneau (1974) and Jameson (1988) requires only the solution of a single linear system of equations per gradient evaluation independent of the number of design variables. Both continuous and discrete adjoint formulations have been used with great success in aerodynamic optimization based on the solution of the Euler equations (Reuther et al., 1999) and the Navier-Stokes equations (Nemec and Zingg, 2002a). Nemec and Zingg (2002b) used the discrete adjoint method for multi-point and

\footnotetext{
${ }^{6}$ Including the TORNADO solver developed by the authors as well as many of the second author's graduate students.
} 
multi-objective optimization, generating a Pareto front for trade-off studies.

Genetic algorithms provide an alternative to gradient-based methods that is more forgiving of a noisy design space and is entirely separate from the flow solver. Consequently, genetic algorithms can be applied to any flow solver with a minimum of effort. Furthermore, they are relatively easy to parallelize. However, a gradient-based algorithm using the adjoint method can be much faster to converge to the optimum. Pulliam et al. (2003) estimate the adjoint approach to be roughly thirty times faster than a genetic algorithm in generating a Pareto front for a two-dimensional design problem. Therefore, if an optimization algorithm is to receive heavy use, as in an industrial environment, the initial programming cost of the adjoint method is a worthwhile investment. Some sort of a hybrid algorithm combining the advantages of both gradient-based and evolutionary algorithms may provide a robust approach.

Numerical optimization techniques have tremendous potential as a design tool, especially for non-traditional geometries and layouts where optimal designs are less wellestablished. The designer is freed from the tedious task of searching the design space and thus can spend more time on the definition of objectives and constraints.

\section{Challenges and Opportunities}

CFD provides an effective tool for aerodynamic design. It has greatly reduced the reliance on wind-tunnel testing, and there exist many examples of aerodynamic modifications that proceeded directly from computational design to flight test, bypassing the wind-tunnel test phase altogether (Eggleston et al., 2002). Nevertheless, there remains considerable need for improvement. The three most basic challenges still remain: efficiency, reliability, and accuracy. Efficiency can be measured in terms of the human effort and expertise required to achieve a suitably accurate solution as well as the computing resources needed. Improvements in mesh generation capabilities and convergence reliability are needed to reduce the human component. Despite improvements in computing power and price-performance ratio, it is still desirable to develop more efficient algorithms. Simply put, a more efficient algorithm produces results of adequate accuracy in an appropriate turnaround time on a less costly computer.

The emphasis on reducing human resource requirements suggests that unstructured meshes combined with solution adaptation and accurate error bounds will come to be the approach of choice (unless Cartesian meshes can be successfully applied to high-Reynolds-number turbulent flows). Research in solution-adaptive meshing must concentrate on starting with a crude mesh (as demonstrated by Habashi et al. (1998)) and must become more rigorous in quantifying the costs of adaptation and the associated reduction in numerical error. Error estimators must incorporate mesh quality; it should not be introduced after the fact. Furthermore, every CFD solution should provide an upper bound on the numerical error in the quantities of interest.

Turbulence remains a primary source of physical-model error (as opposed to numerical error). While today's turbulence models are accurate for many flows of interest, there are also many flows for which they are inadequate. Detached eddy simulation may substantially increase the range of flows that can be computed accurately with a reasonable computational effort; however, more research must be done before this approach can be used with sufficient confidence. Despite the importance of accurate prediction of laminar-turbulent transition, there exists no transition prediction methodology suitable for routine use in aerodynamic computations, i.e., there is no thoroughly validated methodology that is easy to build into a Navier-Stokes solver. Recent work by Edwards et al. (2001) is a promising step.

There is great potential for further advances in aerodynamic optimization. For some applications, such as turbomachinery, it is necessary to optimize a shape exposed to an unsteady flow. Recent work by Duta et al. (2002) and Nadarajah et al. (2003) has made excellent progress toward such a capability. Furthermore, high-fidelity multi-disciplinary optimization will become increasingly feasible. Martins et al. (2002) have developed an efficient coupled adjoint approach applicable to combined aerodynamic and structural optimization. Surrogates, variable-fidelity modeling, pattern-search methods, and various ideas from the domain of artificial intelligence have the potential to greatly advance the field of aerodynamic optimization.

Increases in computer power will also open up new avenues, especially in the development of flow control and smart wings. The combination of LES or DNS with numerical optimization can be used in the design of noise- and turbulence-suppression technologies. CFD and optimization can also be used in the design and operation of morphing wings that adjust to provide optimal performance under variable operating conditions.

Finally, the civil aviation community will receive a severe jolt in the near future as regulatory agencies respond to the increasing need to reduce greenhouse gas emissions (Green, 2003). Unless the impact on climate change per passenger kilometre can be reduced, regulations will prevent further expansion of air travel. The aeronautics community must respond quickly to find technological solutions. The need to reduce emissions puts a new emphasis on drag reduction beyond that motivated by economics alone. This in turn will motivate consideration of radical nontraditional designs. When combined with progressive, creative thinking, the new capabilities under development in aerodynamic and multidisciplinary optimization will provide excellent tools to aid in undertaking the important challenge we collectively face.

\section{REFERENCES}

Aftosmis, M.J., Berger, M.J., and Melton, J.E. (1998). "Robust and Efficient Cartesian Mesh Generation for Component-Based Geometry". AIAA J. Vol. 36, pp. 952-960. 
Aftosmis, M.J., and Berger, M.J. (2002). "Multilevel Error Estimation and Adaptive $h$-Refinement for Cartesian Meshes with Embedded Boundaries". AIAA Pap. No. 2002-0863.

Allen, J.E. (1970). "Looking Ahead in Aeronautics". The Future of Aeronautics, Royal Aeronautical Society, edited by J.E. Allen and J. Bruce. Hutchison \& Co., London. pp. 1-23.

Anderson, J.D., Jr. (1997). "A History of Aerodynamics", Cambridge University Press, Cambridge, U.K.

Arrowheads. (1980). "Avro Arrow: The Story of the Avro Arrow from its Evolution to its Extinction", Boston Mills Press, Erin, Ontario.

Ashley, H., and Landahl, M. (1965). "Aerodynamics of Wings and Bodies", Addison-Wesley Publishing Co. Inc., Reading, Massachusetts.

Bailey, H.E., and Beam, R.M. (1991). Newton's Method Applied to FiniteDifference Approximations for the Steady-State Compressible Navier-Stokes Equations". J. Comput. Phys. Vol. 93, pp. 108-127.

Barber, D.J. (1983). "Large-Scale Propeller Testing in the NRC 9-Metre Wind Tunnel in Canada”. SAE Pap. 830751.

Barker, D.A. (1978). "Toronto Island Airport Study Program: Conclusions and Recommendations". Commissioner of Planning, City of Toronto Planning Board, Ref. 520/74044-04, June 9th, Toronto, Ontario.

Barth, T.J. (1995). "Aspects of Unstructured Grids and Finite-Volume Solvers for the Euler and Navier-Stokes Equations". Von Karman Institute Lecture Series, 1994-05, revised February.

Barth, T.J., and Jespersen, D.C. (1989). "The Design and Application of Upwind Schemes on Unstructured Grids". AIAA Pap. No. 89-0366.

Bauer, F., Garabedian, P., and Korn, D. (1977). "Supercritical Wing Sections III". Lecture Notes in Economics and Mathematical Systems, Springer-Verlag, Berlin

Beam, R., and Warming, R.F. (1978). "An Implicit Finite-Difference Algorithm for Hyperbolic Systems in Conservation Law Form". J. Comput. Phys. Vol. 22, pp. 87-110.

Beam, R., and Warming, R.F. (1976). "An Implicit Factored Scheme for the Compressible Navier-Stokes Equations". AIAA J. Vol. 16, pp. 393-402.

Benek, J.A., Buning, P.G., and Steger, J.L. (1985). "A 3-D CHIMERA Grid Embedding Technique". AIAA Pap. No. 85-1523, July.

Berger, M.J. (1984). "Adaptive Mesh Refinement for Hyperbolic Partial Differential Equations”. J. Comput. Phys. Vol. 53, pp. 484-512.

Boerstoel, J.W. (1975). "Review of the Application of Hodograph Theory to Transonic Aerofoil Design and Theoretical and Experimental Analysis of Shock-free Aerofoils". Symposium Transsonicum II, Springer-Verlag, Berlin.

Borst, H.V. (1973). "Summary of Propeller Design Procedures and Data, Vol. I - Aerodynamic Design and Installation”. Report No. AD-774831, USA AMROL-TR-73-34A. Henry V. Borst \& Associates, Rosemont, Pennsylvania.

Bowman, M.W. (1990). "The World's Fastest Aircraft”, Patrick Stephens Ltd., Wellingborough.

Brandt, A. (1977). "Multilevel Adaptive Solutions to Boundary-Value Problems". Math. Comput. Vol. 31, pp. 333-390.

Briley, W.R., and MacDonald, H. (1977). "Solution of the Multidimensional Compressible Navier-Stokes Equations by a Generalized Implicit Method". J. Comput. Phys. Vol. 24, pp. 372-397.

Buller, F.H., and Toplis, A.F. (1972). "The DHC-7, First Generation Transport Category STOL - Particular Design Challenges". AIAA Pap. 72 809.

Canadian Aviation. (1972). "DHC Augmentor Wing: First Flight Test Report", Canadian Aviation, November.

CASI. (1967). "Canadian Aeronautical and Space History: 100 Years to 1967 Centennial". CASI video. Canadian Aeronautics and Space Institute, Ottawa, Ontario.
Cebeci, T., and Smith, A.M.O. (1974). "Analysis of Turbulent Boundary Layers", Academic Press, New York.

Davy, M.C.W. (1984). "Developing the Regional Airliner", presented at Hi Tech Update '84, Carlton University, December.

Day, R.E. (1997). "Coupling Dynamics in Aircraft: A Historical Perspective". NASA SP-532.

De Rango, S., and Zingg, D.W. (2001). "A High-Order Spatial Discretization for Turbulent Aerodynamic Computations". AIAA J. Vol. 39, pp. 1296-1304.

Dow, J. (1979). "The Arrow", James Lorimer \& Co., Toronto, Ontario.

Drela, M. (1993). "Design and Optimization Method for Multi-Element Airfoils". AIAA Pap. No. 93-0969, February.

Drela, M., Giles, M., and Thompkins, W.T. (1984). "Newton Solution of Coupled Euler and Boundary-Layer Equations". Numerical and Physical Aspects of Aerodynamic Flows III, edited by T. Cebeci. Springer-Verlag, New York.

Drela, M., and Giles, M.B. (1987). "ISES: A Two-Dimensional Viscous Aerodynamic Design and Analysis Code". AIAA Pap. 87-0424.

Durand, W.F. (Editor). (1936). "Aerodynamic theory: a general review of progress", Vols. 1-6. Springer, Berlin.

Duta, M.C., Giles, M.G., and Campobasso, M.S. (2002). "The Harmonic Adjoint Approach to Unsteady Turbomachinery Design”. Int. J. Numer. Methods Fluids, Vol. 40, pp. 323-332.

Edwards, J.R., Roy, C.J., Blottner, F.G., and Hassan, H.A. (2001). "Development of a One-Equation Transition/Turbulence Model". AIAA J., Vol. 39, pp. 1691-1698.

Eggleston, B. (1977). "An Inverse Method for the Design of Airfoils with Supercritical Flow”. SAE Pap. 770450.

Eggleston, B. (1978). "Prospects for Energy Conserving STOL Transports using Prop-Fans". Can. Aeronaut. Space J. Vol. 24, No. 4, pp. 201-216.

Eggleston, B. (1984). "R \& D in the Evolution of the Dash 8". Can. Aeronaut. Space J. Vol. 30, No. 3, September, pp. 195-212.

Eggleston, B., and Barber, D.J. (1987). "An Update on Propeller R\&D at de Havilland Canada", Proceedings of the CASI AGM, 25-26 May 1987, Toronto, Ontario.

Eggleston, B., and Jones, D.J. (1985). "The Development of Thick, Low Drag Supercritical Airfoils". Proceedings of the CASI Aerodynamics Symposium, 27-28 May 1985, Montreal, Quebec.

Eggleston, B., McKinney, B., Banaszek, J., Choi, N.S., Krolikowski, G., Lebrun, F., Thompson, J., Zingg, D.W., Nemec, M., and De Rango, S. (2002). "Development of a New Flap for a Light Utility Transport Airplane". Can. Aeronaut. Space J. Vol. 48, No. 4, pp. 233-238.

Eiseman, P.R., and Smith, R.E. (1980). "Grid Generation Using Algebraic Techniques”. NASA, CP-2166, pp. 73-120.

Epstein, B., Lutz, A.L., Nachson, A. (1989). "Multigrid Transonic Computations about Arbitrary Aircraft Configurations". J. Aircr. Vol. 26, No. 8, August.

Fejtek, I. (1997). "Summary of Code Validation Results for a Multiple Element Test Case". AIAA Pap. No. 97-1932.

Fejtek, I. (2001). "Computational Aerodynamics at Bombardier Aerospace Toronto". Proceedings of the 8th Aerodynamics Symposium, 29 April - 2 May 2001, Toronto, Ontario. pp. 1-14.

Fejtek, I., Jones, G.D., Waller, G., Hansen, E., and Obayashi, S. (2001). "A Transonic Wing Inverse Design Capability for Complete Aircraft Configurations". AIAA Pap. 2001-2443.

Giles, M.B., and Drela, M. (1987). "Two-Dimensional Transonic Aerodynamic Design Method". AIAA J. Vol. 25, pp. 1199-1206. 


\section{Canadian Aeronautics and Space Journal Journal aéronautique et spatial du Canada}

Giles, M.B., and Pierce, N.A. (2002). "Adjoint Error Correction for Integral Outputs". In Error Estimation and Adaptive Discretization Methods in Computational Fluid Dynamics", edited by T. Barth and H. Deconinck. Lecture Notes in Computational Science and Engineering, Vol. 25, pp. 47-96.

Godin, P., Zingg, D.W., and Nelson, T.E. (1997). "High-Lift Aerodynamic Computations with One- and Two-Equation Turbulence Models". AIAA J. Vol. 35, pp. 237-243.

Godunov, S.K. (1959). "A Difference Scheme for Numerical Computation of Discontinuous Solutions of Hydrodynamic Equations". Math. Sbornik, Vol. 47, pp. 271-306 (in Russian), translated by US Joint Publ. Res. Service, JPRS 7226, 1969.

Green, J.E. (2003). "Civil Aviation and the Environmental Challenge". Aeronaut. J. June, pp. 281-299.

Green, J.E., Weeks, D.G., and Brooman, J.W.F. (1973). "Prediction of Turbulent Boundary Layers and Wakes in Compressible Flow by a LagEntrainment Method". Aeronautical Research Council, R\&M 3791, London.

Habashi, W.G., Dompierre, J., Bourgault, Y., Fortin, M., and Vallet, M.-G. (1998). "Certifiable Computational Fluid Dynamics Through Mesh Optimization”. AIAA J. May. Vol. 36, No. 5, pp. 703-711.

Hager, R.D., and Vrabel, D. (1988). “Advanced Turboprop Project”. NASA SP-495.

Hallion, R.P. (1984a). "Rise of the Fighter Aircraft: 1914-1918”, Nautical \& Aviation Publishing Company of America Inc., Annapolis, Maryland.

Hallion, R.P. (1984b). "On the Frontier, Flight Research at Dryden 19461981”. NASA SP-4303.

Harten, A. (1983). "High Resolution Schemes for Hyperbolic Conservation Laws". J. Comput. Phys. Vol. 49, pp. 357-393.

Harten, A., and Osher, S. (1987). "Uniformly High-Order Accurate NonOscillatory Schemes”. SIAM J. Numer. Anal. Vol. 24, pp. 279-309.

Harten, A., Enquist, B., Osher, S., and Chakravarthy, S.R. (1987). "Uniformly High-Order Accurate Essentially Non-Oscillatory Schemes III". J. Comput. Phys. Vol. 71, pp. 231-303.

Hess, J.L., and Smith, A.M.O. (1966). "Calculation of Potential Flow About Arbitrary Bodies”. Prog. Aeronaut. Sci. Vol. 8.

Hicks, R.M., Murman, E.M., and Vanderplaats. (1974). "An Assessment of Airfoil Design by Numerical Optimization". NASA, TM X-3092.

Hodges, A. (2000). "Alan Turing: The Enigma”, Walker \& Co., New York.

Holst, T.L. (1987). "Viscous Transonic Airfoil Workshop Compendium of Results". AIAA Pap. No. 87-1460.

Holst, T.L., and Ballhaus, W.F. (1979). "Fast, Conservative Schemes for the Full Potential Equation Applied to Transonic Flows". AIAA J. Vol. 17, No. 2, February, pp. 145-152.

Jackson, G.R. (1982). "The Dash 8 - Design Considerations". SAE Pap. 820728.

Jameson, A. (1973). "Numerical Calculation of the Three-dimensional Transonic Flow Over a Yawed Wing". Proceedings of the AIAA CFD Conference, Palm Springs, July,

Jameson, A. (1983). "Solution of the Euler Equations for Two-Dimensional Transonic Flow by a Multigrid Method". Appl. Math. Comput. Vol. 13, pp. 327-355.

Jameson, A. (1988). "Aerodynamic Design via Control Theory". J. Sci. Comput. Vol. 3, pp. 233-260.

Jameson, A., Schmidt, W., and Turkel, E. (1981). "Numerical Solution of the Euler Equations by Finite-Volume Methods Using Runge-Kutta Schemes". AIAA Pap. No. 81-1259.

Jespersen, D., Pulliam, T., and Buning, P. (1997). "Recent Enhancements to OVERFLOW". AIAA Pap. No. 97-0644.
Jones, R.T. (1946). "Properties of Low Aspect-Ratio Pointed Wings at Speeds Below and Above the Speed of Sound". NACA Rep. 835.

Jones, R.T. (1947). "Wing Plan Forms for High Speed Flight". NACA Rep. 863.

Jones, R.T. (1956). "Theory of Wing-Body Drag at Supersonic Speeds". NACA Rep. 1284.

Jones, R.T. (1990). "Wing Theory”, Princeton University Press, Princeton, New Jersey.

Kafyeke, F. (1997). "CFD for the Aerodynamic Design of Bombardier's Global Express High Performance Jet". AIAA Pap. 97-2269.

Lax, P.D. (1954). "Weak Solutions of Nonlinear Hyperbolic Equations and Their Numerical Computation". Commun. Pure Appl. Math. Vol. 7, pp. 159193.

Lax, P. (1972). "Hyperbolic Systems of Conservation Laws and the Mathematical Theory of Shock Waves", SIAM, Philadelphia, Pennsylvania.

Lax, P.D., and Wendroff, B. (1960). "Systems of Conservation Laws". Commun. Pure Appl. Math. Vol. 13, pp. 217-237.

LeBalleur, J.C. (1982). "Viscid-Inviscid Coupling Calculations for Two and Three Dimensional Flows". Computational Fluid Dynamics, Von Karman Institute for Fluid Dynamics Lecture Series, 1982-04.

Liebeck, R.H. (1973). "A Class of Airfoils Designed for High Lift in Incompressible Flow". J. Aircr. Vol. 10, pp. 610-617.

Lock, R.C. (1981). "A Review of Methods for Predicting Viscous Effects on Aerofoils and Wings at Transonic Speeds". AGARD, CP 291.

Lomax, H., and Baldwin, B. (1978). "Thin-Layer Approximation and Algebraic Model for Separated Turbulent Flows". AIAA Pap. No. 78-257.

Lomax, H., Pulliam, T.H., and Zingg, D.W. (2001). "Fundamentals of Computational Fluid Dynamics", Springer-Verlag, New York.

Lukasiewicz, J. (2000). “Canada's Encounter with High-Speed Aeronautics". CASI Log Vol. 8, No. 5, October, pp. 8-25.

Lye, J.D. (1987). "Recent Developments in Augmentor-Wing Aerofoil Sections".CASI AGM Paper.?

Lye, J.D., Buchholz, S., and Nickison, D. (2002). "Testing of a Dash 8 Q400 in the NASA Ames $80 \times 120$ Wind Tunnel". ICAS Pap. 3103 .

Lynch, F.T. (1981). "Commercial Transports - Aerodynamic Design for Cruise Performance Efficiency". In Transonic Aerodynamics, edited by D. Nixon. AIAA Prog. Astronaut. Aeronaut. Vol. 81, pp. 81-147.

MacCormack, R.W. (1969). "The Effect of Viscosity in Hypervelocity Impact Cratering". AIAA Pap. No. 69-354, April.

MacCormack, R.W. (1993). "A Perspective on a Quarter Century of CFD Research". AIAA Pap. No. 93-3291, July.

Martinelli, L., Jameson, A., and Grasso, F. (1986). "A Multigrid Method for the Navier-Stokes Equations". AIAA Pap. No. 86-0208.

Martins, J.R.R.A., Alonso, J.J., and Reuther, J.J. (2002). High-Fidelity Aero-Structural Design Optimization of a Supersonic Business Jet". AIAA Pap. No. 2002-1483.

Maskew, B. (1982). "Predictions of Subsonic Aerodynamic Characteristics: A Case for Low-Order Panel Methods". J. Aircr. Vol. 19, No. 2, February, pp. 157-163.

Mavriplis, D.J. (1990). "Accurate Multigrid Solution of the Euler Equations on Unstructured and Adaptive Meshes". AIAA J. Vol. 28, No. 2, pp. 213-221.

Mavriplis, D.J. (1995). "Three-Dimensional Multigrid Reynolds-Averaged Navier-Stokes Solver for Unstructured Meshed". AIAA J. Vol. 33, No. 3, pp. $445-453$.

Menter, F.R. (1993). "Zonal Two-Equation $k-\omega$ Models for Aerodynamic Flows". AIAA Pap. No. 93-2906. 
Miller, R., and Sawers, D. (1968). "The Technical Development of Modern Aviation", Routledge \& Kegan Paul, London.

Moretti, G. (1979). "The Lambda Scheme”. Comput. \& Fluids, Vol. 7, pp. 191-205.

Morgan, M.B., and Thomas, H.H.B.M. (1945). "Control Surface Design: in Theory and Practice", August, Royal Aeronautical Society, London.

Murman, E.M., and Cole, J.D. (1971). "Calculation of Plane Steady Transonic Flows". AIAA J. Vol. 9, No. 1, January, pp. 114-121.

Murman, S.M., Aftosmis, M.J., and Berger, M.J. (2003). "Simulations of 6DOF Motion with a Cartesian Method". AIAA Pap. No. 2003-1246.

Nadarajah, S.K., McMullen, M.S., and Jameson, A. (2003). "Optimum Shape Design for Unsteady Flow Using Time Accurate and Nonlinear Frequency Domain Methods". AIAA Pap. No. 2003-3875.

NASA. (2004). "Ames Research Center 2004 Implementation Plan".

Nelson, T.E., Zingg, D.W., and Johnston, G.W. (1994). "Compressible Navier-Stokes Computations of Multielement Airfoil Flows using Multiblock Grids". AIAA J. Vol. 32, No. 3, pp. 506-511.

Nemec, M., and Zingg, D.W. (2002a). "Newton-Krylov Algorithm for Aerodynamic Design using the Navier-Stokes Equations". AIAA J. Vol. 40, pp. 1146-1154.

Nemec, M., and Zingg, D.W. (2002b). "Multi-Point and Multi-Objective Aerodynamic Shape Optimization". AIAA Pap. No. 2002-5548.

Ohman, L.H., Nguyen, V.D., Ellis, F., Thain, J., Tang, N., Broughton, C., Mebarki, Y., Ficner, J., and Bureau, J. (2001). "The IAR 1.5m Trisonic Blowdown Wind Tunnel: A Review of Its History and Development”. Can. Aeronaut. Space J. Vol. 47, No. 3, September, pp. 163-173.

Ollivier-Gooch, C. (1997). "Quasi-ENO Schemes for Unstructured Meshes Based on Unlimited Data-Dependent Least-Squares Reconstruction". J. Comput. Phys. Vol. 133, pp. 6-17.

Osher, S. (1984). "Riemann Solvers, Entropy Condition and Difference Approximations". SIAM J. Numer. Anal. Vol. 21, pp. 217-235.

Pearcey, H.H. (1962). "The Aerodynamic Design of Section Shapes for Swept Wings". Advances in Aeronautical Sciences, Vol. 3. Pergamon Press, Oxford.

Pearcey, H.H., and Osborne, J. (1970). "Some Problems and Features of Transonic Aerodynamics". ICAS Pap. 70-14.

Piperni, P., and Boudreau, J. (2003). "The Evolution of Structured Grid Generation at Bombardier Aerospace". Proceedings of the 9th Aerodynamics Symposium of the Canadian Aeronautics and Space Institute, Canadian Aeronautics and Space Institute, Ottawa, Ontario.

Pironneau, O. (1974). "On Optimum Design in Fluid Mechanics”. J. Fluid Mech. Vol. 64, pp. 97-110.

Pleines, W. (1961). "Application of the Slotted Wing to Steep Gradient and STOL Aircraft". Boundary Layer and Flow Control, edited by G.V. Lachmann. Permgamon Press, Oxford. pp. 424-447.

Poole, R.J.D., and Teeling, P. (1981). "Airfoils for Light Transport Aircraft". SAE Pap. 810576, April.

Poppen, W.A., Smith, B.E., and Lye, J.D. (1991). "Propulsion-Induced Aerodynamics of an Ejector-Configured STOVL Fighter Aircraft". AIAA Pap. 91-0765.

Pueyo, A., and Zingg, D.W. (1998). "Efficient Newton-Krylov Solver for Aerodynamic Computations". AIAA J. Vol. 36, pp. 1991-1997.

Pulliam, T.H. (1986). "Efficient Solution Methods for the Navier-Stokes Equations". In Numerical Techniques for Viscous Flow Computation in Turbomachinery Bladings. Von Karman Institute for Fluid Dynamics, Lecture Series VKI LS1986-02, Brussels.
Pulliam, T.H., and Chaussee, D.S. (1981). "A Diagonal Form of an Implicit Approximate Factorization Algorithm". J. Comput. Phys. Vol. 39, pp. 347363

Pulliam, T.H., and Steger, J.L. (1980). "Implicit Finite-Difference Simulations of Three-Dimensional Compressible Flow". AIAA J. Vol. 19, p. 159.

Pulliam, T.H., Nemec, M., Holst, T., and Zingg, D.W. (2003). "Comparison of Evolutionary (Genetic) Algorithm and Adjoint Methods for MultiObjective Viscous Airfoil Optimizations". AIAA Pap. No. 2003-0298, January.

Reuther, J.J., Alonso, J.J., Rimlinger, M.J., and Jameson, A. (1999). "Aerodynamic Shape Optimization of Suopersonic Aircraft Configurations via an Adjoint Formulation on Distributed Memory Parallel Computers". Comput. \& Fluids, Vol. 28, pp. 675-700.

Roe, P.L. (1981). "Approximate Riemann Solvers, Parameter Vectors, and Difference Schemes”. J. Comput. Phys. Vol. 43, pp. 357-372.

Roe, P.L. (1986). "Characteristics-Based Schemes for the Euler Equations". Аnnu. Rev. Fluid Mech. Vol. 18, pp. 337-365.

Rumsey, C.L., and Ying, S.X. (2002). "Prediction of High Lift: Review of Present CFD Capability”. Prog. Aerospace Sci. Vol. 38, pp. 145-180.

Rumsey, C.L., Lee-Rausch, E.M., and Watson, R.D. (2003). "ThreeDimensional Effects in Multi-Element High Lift Computations". Comput. \& Fluids, Vol. 32, pp. 631-657.

Saad, Y., and Schultz, M.H. (1986). "GMRES: A Generalized Minimal Residual Algorithm for Solving Nonsymmetric Linear Systems". SIAM J. Sci. Statist. Comput. Vol. 7, pp. 856-869.

Sachdev, J.S., Groth, C.P.T., and Gottlieb, J.J. (2003). "A Parallel SolutionAdaptive Scheme for Predicting Multi-Phase Core Flows in Solid Propellant Rocket Motors". Submitted to Int. J. Comput. Fluid Dynam.

Shang, J.S., and Hankey, W.L. (1975). "Numerical Solution for Supersonic Turbulent Flow Over a Compression Ramp". AIAA J. Vol. 13, No. 10, October, pp. 1368-1374.

Spaid, F.W., Dahlin, J.A., Bachalo, W.D., Stivers, L.S., Jr. (1983). "An Experimental Study of Transonic Flow About a Supercritical Airfoil". NASA TM 81336.

Spalart, P.R. (2000). "Trends in Turbulence Treatments". AIAA Pap. No. 2000-2306.

Spalart, P.R. (2001). "Young-Person's Guide to Detached-Eddy Simulation Grids". NASA, CR-2001-211032.

Spalart, P.R., and Allmaras, S.R. (1992). "A One-Equation Turbulence Model for Aerodynamic Flows". AIAA Pap. No. 92-0439.

Steger, J.L., and Chaussee, D. (1980). "Generation of Body-Fitted Coordinates Using Hyperbolic Partial Differential Equations". SIAM J. Sci. Statist. Comput. Vol. 1, pp. 431-437.

Steger, J., and Warming, R.F. (1981). "Flux Vector Splitting of the Invisicid Gasdynamic Equations with Application to Finite-Difference Methods". J. Comput. Phys. Vol. 40, No. 2, pp. 263-293.

Stewart, G. (1988). "Shutting Down the National Dream: A.V. Roe and the Tragedy of the Avro Arrow", McGraw-Hill Ryerson, Scarborough, Ontario.

Stratford, A.H. (1970). "Airports and Air Transport; Growth and Transformation". The Future of Aeronautics, Royal Aeronautical Society, edited by J.E. Allen and J. Bruce. Hutchison \& Co., London.

Stratford, B.S. (1959). "The Prediction of Separation of the Turbulent Boundary Layer". J. Fluid Mech. Vol. 5, pp. 1-16.

Swanson, R.C., and Turkel, E. (1992). "On Central-Difference and Upwind Schemes”. J. Comput. Phys. Vol. 101, No. 2, pp. 292-306. 
Tanguay, B., Nguyen, V.D., Cooper, K., Larose, G., and Desauriers, M. (2001). "The Revitalization and Rejuvenation of the IAR $9 \mathrm{~m} \times 9 \mathrm{~m}$ Wind Tunnel”. Can. Aeronaut. Space J. Vol. 47, No. 3, September, pp. 190-196.

Thompson, J.F., Warsi, Z.U.A., and Mastin, C.W. (1985). "Numerical Grid Generation: Foundations and Applications", North-Holland, New York.

Tinoco, E.N. (1998). "The Impact of Computational Fluid Dynamics in Aircraft Design”. Can. Aeronaut. Space J. Vol. 44, No. 3, pp. 132-144.

Trepanier, J.-Y., Zhang, H., Reggio, M., and Camarero, R. (1991). "Adaptive and Moving Meshes for the Computation of Unsteady Compressible Flows". Proceedings of the 3rd International Conference on Numerical Grid Generation in Computational Fluid Dynamics and Related Fields, Barcelona, Spain, 3-7 June 1991, edited by A.S. Arcilla, J. Hauser, P.R. Eiseman, and J.F. Thompson. North-Holland, New York. pp. 43-54.

Van Leer, B. (1979). "Towards the Ultimate Conservative Difference Schemes V - A Second-Order Sequel to Godunov's Method". J. Comput. Phys. Vol. 32.

Van Leer, B. (1982). "Flux Vector Splitting for the Euler Equations". Proceedings of the 8th International Conference on Numerical Methods in Fluid Dynamics, Aachen, Germany, 28 June - 2 July 1982, edited by E. Krause. Springer-Verlag, Berlin.

Venditti, D.A., and Darmofal, D.L. (2003). "Anisotropic Grid Adaptation for Functional Outputs: Application to Two-Dimensional Viscous Flows". J. Comput. Phys. Vol. 187, pp. 22-46.

Venkatakrishnan, V. (1995). "Convergence to Steady State Solutions of the Euler Equations on Unstructured Grids with Limiters". J. Comput. Phys. Vol. 118, pp. 120-130.

Venkatakrishnan, V. (1996). "Perspective on Unstructured Grid Flow Solvers". AIAA J. Vol. 34, No. 3, pp. 533-546.

Venkatakrishnan, V., and Mavriplis, D.J. (1993). "Implicit Solvers for Unstructured Meshes". J. Comput. Phys. Vol. 105, pp. 83-91.

Venkateswaran, S., and Merkle, C.L. (1995). "Dual Time Stepping and Preconditioning for Unsteady Computations". AIAA Pap. No. 95-0078.

Vinokur, M. (1974). "Conservation Equations of Gasdynamics in Curvilinear Coordinate Systems". J. Comput. Phys. Vol. 14, pp. 105-125.

Von Neumann, J., and Richtmyer, R.D. (1950). "A Method for the Numerical Calculation of Hydrodynamic Shocks". J. Appl. Phys. Vol. 21, pp. 232-237.

Weatherill, N.C., and Forsey, C.R. (1984). "Grid Generation and Flow Calculations for Complex Aircraft Geometries Using a Multi-Block Scheme". AIAA Pap. No. 84-1665.

Whitcomb, R.T. (1956). "A Study of the Zero-Lift Drag-Rise Characteristics of Wing-Body Combinations Near the Speed of Sound". NACA Rep. 1273.

Whitcomb, R.T. (1965). "An Airfoil Shape for Efficient Flight at Supercritical Mach Numbers". NASA TM-X-1109.

Whitcomb, R.T, and Sevier, J.R., Jr. (1960). "A Supersonic Area Rule and an Application to the Design of a Wing-Body Combination with High-LiftDrag Ratios". NASA Rep. 72.

Whittley, D.C. (1967). “The Augmentor-Wing Research Program: Past, Present and Future". AIAA Pap. 67-741. pp. 10-21.

Whittley, D.C. (1976). "Recent Canadian Technical Developments in STOL". Aerospace, Royal Aeronautical Society, Vol. 3, No. 10, December, pp. 10-21.

Whittley, D.C., and Koenig, D.G. (1980). "Large Scale Model Tests of a New Technology V/STOL Concept”. AIAA Pap. 80-0233.

Yee, H. (1985). "Generalized Formulation of a Class of Explicit and Implicit TVD Schemes". NASA, TM 86775.
Zan, S.J., Cooper, K.R., and Ball, N.G. (2001). "The IAR $2 \mathrm{~m} \times 3 \mathrm{~m}$ LowSpeed Wind Tunnel: Its Development and Contribution to Aeronautics in Canada". Can. Aeronaut. Space J. Vol. 47, No. 3, September, pp. 269-274.

Zierep, J., and Oertel, H. (1989). "Symposium Transsonicum III.” IUTAM Symposium, Gottingen, 24-27 May 1988. Springer-Verlag, Berlin.

Zingg, D.W. (1983). "An Approach to the Design of Airfoils with High Lift to Drag Ratios". University of Toronto Institute for Aerospace Studies, Tech. Note 245.

Zingg, D.W. (1992). "Grid Studies for Thin-Layer Navier-Stokes Computations of Airfoil Flowfields". AIAA J. Vol. 30, pp. 2561-2564.

Zingg, D.W., De Rango, S., Nemec, M., and Pulliam, T.H. (2000). "Comparison of Several Spatial Discretizations for the Navier-Stokes Equations”. J. Comput. Phys. Vol. 160, pp. 683-704.

Zingg, D.W., Nemec, M., and Chisholm, T. (2003). "A Newton-Krylov Algorithm for Aerodynamic Analysis and Design". In Proceedings of the 2nd International Conference on Computational Fluid Dynamics 2002, Sydney, Australia, 15-19 July 2002, edited by S. Armfield, P. Morgan, and K. Srinivas. Springer, Berlin, Germany. 